\title{
A global perspective on macroprudential policy interaction with systemic risk, real economic activity, and monetary intervention
}

\author{
Mikhail I. Stolbov ${ }^{1 *}$ (D) Maria A. Shchepeleva ${ }^{2}$ and Alexander M. Karminsky ${ }^{3}$
}

\author{
${ }^{*}$ Correspondence: \\ stolbov_mi@mail.ru \\ ${ }^{1}$ Chair of the Department \\ of Applied Economics, \\ Moscow State Institute \\ of International Relations \\ (MGIMO University), Moscow, \\ Russia \\ Full list of author information \\ is available at the end of the \\ article
}

\begin{abstract}
The study empirically assesses how macroprudential policy interacts with systemic risk, industrial production, and monetary intervention on a global level from January 2006 to December 2018. We adopt the aggregate proxies of these variables, capturing their global effects, and use a novel econometric technique, namely, smooth local projections. The study finds that global macroprudential policy leads the monetary policy, exhibiting a countercyclical pattern concerning industrial production. The latter has an inverse bidirectional linkage with systemic risk. Thus, an ex-ante tight macroprudential policy can indirectly mitigate global systemic risk through its pro-growth effect on industrial production, although no convincing evidence exists for the direct impact of a macroprudential intervention on systemic risk. The study results endure several extensions and a robustness check, which builds on alternative measures of global systemic stress and real economic activity, thereby legitimizing the increased importance attached to the macroprudential policy since the 2007-2009 global financial crisis.
\end{abstract}

Keywords: Industrial production, Macroprudential policy, Monetary policy, Smooth local projections, Systemic risk

JEL Classification: G01, G18, C32

\section{Introduction}

Since the 2007-2009 global financial crisis (GFC), macroprudential policy has been recognized as a tool to mitigate the buildup of systemic risk and severity of financial crises. Although there are numerous theoretical and empirical studies on macroprudential policy, ${ }^{1}$ several challenging issues remain underexplored. For instance, coordination between macroprudential and monetary policy at the national level should be thoroughly investigated (Gambacorta and Murcia 2020; Lubis et al. 2019; Revelo et al. 2020; Rubio and Yao 2020). Similarly, the macroeconomic effects of macroprudential policy should be comprehensively assessed, because there is no clear-cut consensus on whether it helps safeguard financial stability while hampering economic growth or, conversely, its

\footnotetext{
${ }^{1}$ See, for example, Galati and Moessner $(2013,2018)$ and Forbes (2019) for excellent surveys on macroprudential policy and its challenges. Furthermore, Araujo et al. (2020) conducted a comprehensive meta-analysis of macroprudential policy effects.
} party material in this article are included in the article's Creative Commons licence, unless indicated otherwise in a credit line to the material. If material is not included in the article's Creative Commons licence and your intended use is not permitted by statutory regulation or exceeds the permitted use, you will need to obtain permission directly from the copyright holder. To view a copy of this licence, visit http:// creativecommons.org/licenses/by/4.0/. 
impact on real economic activity is neutral or even positive (Andries and Melnic 2019; Belkhir et al. 2020; Boar et al. 2017; Davis et al. 2019; Kim and Mehrotra 2019; Madeira 2020; Richter et al. 2019; Rojas et al. 2020). In a cross-country framework, international spillovers of domestic macroprudential intervention should be measured properly, which would facilitate adequate policy coordination among involved countries (Kang et al. 2017; Norring 2019). ${ }^{2}$

This study examines how macroprudential and monetary policies interact with systemic risk, industrial production, and with each other on the global level from January 2006 to December 2018. This is perhaps the first study to assess such aggregate linkages because, owing to the absence of comprehensive cross-country datasets on macroprudential policy, such a global approach has previously been constrained. The compilation of the novel monthly IMF database on macroprudential measures by Alam et al. (2019) has partly mitigated the limitation. Based on this database, we construct an index of macroprudential policy activism across the world. To capture the global monetary policy stance, we use the data from the Council on Foreign Relations (CFR) global monetary policy tracker available from January 2006 onward. This indicator is provided by the Council of Foreign Relations, a US think tank. This series aggregates the dynamics of policy interest rates and the implementation of unconventional monetary policy instruments across several countries. A worldwide measure of conditional capital shortfall (SRISK) proposed by Brownlees and Engle (2017) is our proxy for global systemic risk. We use the world industrial production index by the CPB Netherlands Bureau for Economic Policy Analysis to track the dynamics of global real economic activity.

We apply a novel econometric methodology, namely, smooth local projections by Barnichon and Brownlees (2019), to derive the impulse response functions for a system comprising the four variables. Compared with the conventional vector autoregressions (VARs), the local projections impose weaker assumptions on the dynamics of the underlying data, thereby allowing for more flexible impulse response estimation. Specifically, this methodology is more robust to data nonlinearity and model misspecification. Moreover, smooth local projections are more beneficial than the standard local projections proposed by Jordá (2005), as they do not suffer from excessive variability and thus substantially increase the precision of the impulse response estimation. When applying this econometric technique, we also depart from the premise that along with SRISK and industrial production index, the proxies of global macroprudential and monetary policies are endogenous variables.

By deriving the impulse response functions based on the smooth local projections, we find an inverse bidirectional linkage between systemic risk and industrial production at the global level, that is, an increase in SRISK dampens the dynamics of the world industrial production index, while a rise in the industrial production mitigates the systemic risk. Interestingly, no direct effect of global macroprudential policy on systemic risk is found. Nonetheless, this policy has a positive impact on industrial production, thereby indirectly ameliorating systemic risk through acceleration in real economic activity.

\footnotetext{
${ }^{2}$ Such analysis would extend the traditional literature on international spillovers, e.g. among national stock markets (Karolyi and Stulz 1996; Lu et al. 2019) or related to the propagation of monetary policy effects from the central economies to the peripheral ones (Kucharčuková et al. 2016; Tule et al. 2019).
} 
Moreover, global macroprudential policy leads the monetary policy. Considering that macroprudential measures produce a more immediate effect on industrial production than monetary policy, there is additional scope for global macroprudential intervention relative to monetary policy, especially in the low-interest-rate environment that has been established after the GFC. Higher levels of industrial production entail the tightening of monetary policy. However, the monetary policy tends to be relaxed when systemic risk increases. Thus, similar to global macroprudential policy, the monetary policy is countercyclical with respect to real economic activity.

Our baseline approach is extended in two ways: first, it involves decomposing systemic risk into high and low regimes. To distinguish between the two regimes, we extract a stochastic trend from the SRISK series through a one-sided Hodrick-Prescott (HP) filter and assume positive differences between the actual SRISK values and trend to capture the high-risk regime, while assuming that negative differences capture the low-risk regime. Several additional findings are derived by decomposing SRISK. For instance, the relationships running from SRISK to global industrial production, and vice versa, differ by their magnitude, conditional on a low- or high-risk regime. In the high-risk environment, the responses of both variables are stronger. Besides, the pro-growth effect of macroprudential policy is only observed in the low-risk environment, which disappears in the high-risk environment. The latter finding suggests that preemptive macroprudential policy is beneficial and welfare-enhancing when the systemic risk has not been sufficiently established to materialize.

Our second extension involves dividing the global macroprudential policy activism index into borrower- and financial institution-targeted macroprudential measures. Thus, borrower-targeted macroprudential measures are found to produce a weak dampening effect on systemic risk, while those aimed at financial institutions have no effect at all. However, both measures promote global real economic activity. The rest of the results appear qualitatively similar to our baseline estimations, emphasizing the salient role of global macroprudential policy.

The results of the two extensions corroborate the countercyclical nature of global macroprudential policy. Besides, given the total number and directions of statistically significant impulse responses in which the index of global macroprudential policy activism is involved, the global macroprudential policy played a more substantial role than the monetary policy during the observation period.

We conducted a robustness check comprising two exercises on our baseline results. First, we replaced SRISK with another systemic stress indicator, namely, the Office of Financial Research (OFR) financial stress index proposed by Monin (2019) and used by the US Financial Stability Oversight Council, to monitor global financial stability. This exercise also involves two extensions to the baseline framework, that is, decomposing the OFR financial stress index into high and low regimes and dividing the index of global macroprudential policy activism into sub-indices. In the second exercise, the world industrial production index is replaced with a composite measure of global real economic activity based on the first principal component from the shipping costs index (Hamilton 2021) and GECON, a monthly global economic conditions indicator (Baumeister et al. 2020). Both ingredients of the robustness check support the baseline results. 


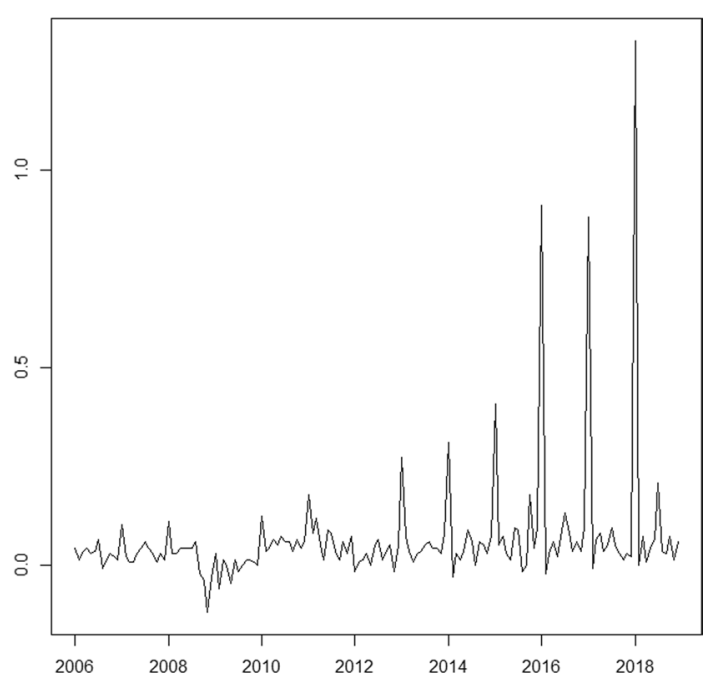

Fig. 1 Dynamics of the iMaPP index

This study is presented as follows. Section "Data" describes the data. Section "Methodology" explains the econometric methodology. Section "Results and discussion discusses the results. Section "Robustness check" describes the robustness check. Section "Conclusions" concludes.

\section{Data}

Our index of macroprudential policy activism (iMaPP) uses the data on 17 macroprudential instruments reported by the IMF integrated Macroprudential Policy Database (Alam et al. 2019) for every country-month observation from January 2006 to December 2018. The data represent dummy-type indices of tightening (coded with 1), loosening actions (coded with -1 ), or no actions (coded with 0 ) for every policy instrument. Thus, to construct our $i M a P P$ index, we first sum up these indices of tightening and loosening for country $i$ in month $t$, and then compute simple monthly averages of the sums across all 134 countries included in the database

$$
i M a P P_{t}=\frac{\sum_{i=1}^{134} \sum_{k=1}^{17} M P I_{i k}}{134},
$$

where $M P I_{i k}$ is a dummy-type index of $k$ th macroprudential instrument for country $i$. The breakdown of the $i M a P P$ index by macroprudential policy measures is reported in Table 3 of the "Appendix", while the countries and regions covered in the index are enlisted in Table 4.

Figure 1 plots the dynamics of the index, indicating no clear-cut upward trend during the observation period, except for the early 2009 to late 2011 period, when most countries synchronously tightened macroprudential measures in the aftermath of the GFC. The stark jumps in the iMaPP index observed in early 2013, 2014, 2015, and 2016 are associated with the implementation of different macroprudential policy measures according to the Basel III Accords. Specifically, in early 2013 and 2014, several countries simultaneously introduced new capital requirements and conservation buffers. In 


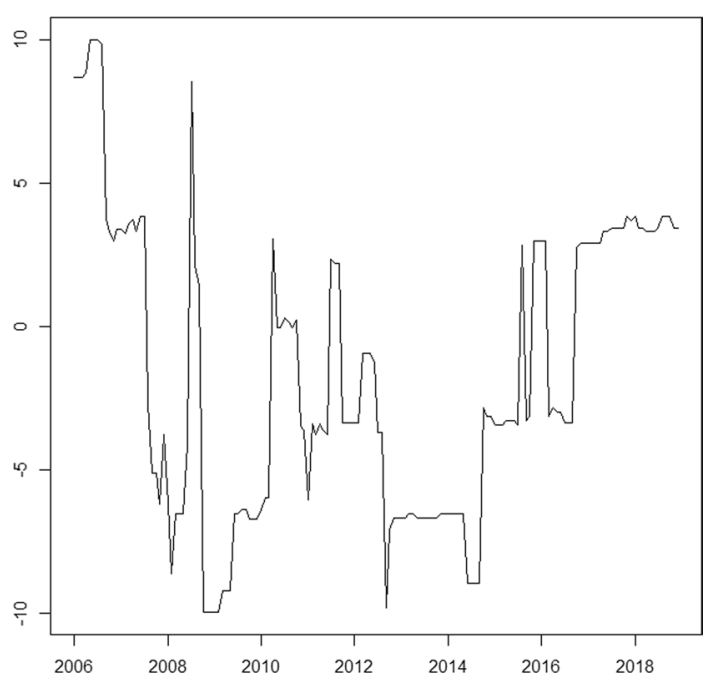

Fig. 2 Dynamics of the MP index

2015, the implementation of liquidity measures increased the index, the liquidity coverage ratio (LCR), in particular. Finally, in 2016 and 2018, the effect was because of the measures taken to mitigate the risks associated with domestic and global systemically important financial institutions.

The CFR global monetary policy tracker provided by the US Council of Foreign Relations $^{3}$ explains the global monetary policy stance (Fig. 2). It builds on the data from 54 major economies (Table 5 of the "Appendix"), capturing the overall trend in the global monetary policy, for example, whether the tightening or easing of policy prevails at that moment. The countries covered in the CFR global monetary policy tracker are fewer compared with the $i M a P P$ index. However, among its 54 constituents, there are countries with the biggest potential to propagate their domestic monetary policy shocks globally, that is, the USA, the EU, Japan, and China. Thus, we argue that the index of global easing or tightening (MP index) based on the CFR global monetary policy tracker adequately captures the variation in the global monetary policy. The MP index assumes the values ranging from -10 (if all 54 countries loosen their monetary policy) to 10 (if they all tighten the policy). This index is unique in that it accounts for both changes in policy interest rates and unconventional policy measures (e.g., in the form of quantitative easing).

In contrast to the $i M a P P$ index, which remained relatively stable before the GFC, the MP index exhibits a strong downward trend for 2006-2007. It reflects the long-run global decline in the interest rates interrupted by a desperate attempt to prevent the outbreak of the crisis in the early 2008. After the eventual outbreak of the crisis, the MP index started to decrease, reaching the minimum level in the spring 2009. Similar to the iMaPP index, the indicator then partly rebounded, which reflects the prevailing trend toward policy tightening after the acute phase of the GFC. However, in 2012 that trend

${ }^{3}$ See https://www.cfr.org/global/global-monetary-policy-tracker/p37726. 
was again reversed, with loose monetary policy dominating the world economy until the early 2015.

This study adopts the conditional capital shortfall (SRISK) as a proxy of systemic risk (Brownlees and Engle 2017). SRISK can be represented as follows:

$$
S_{R I S K}{ }_{i t}=k D_{i t}-(1-k) W_{i t}\left(1-L R M E S_{i t}\right)=W_{i t}\left[k L V G_{i t}+(1-k) L R M E S_{i t}-1\right],
$$

where $W_{i t}$ denotes the market value of equity, $D_{i t}$ is the book value of debt, and $k$ refers to the prudential capital adequacy ratio. Long-run marginal expected shortfall $\left(L R M E S_{i t}\right)$ measures the sensitivity of a financial institution's equity value to the severe market decline, while $L V G_{i t}$ is the so-called quasi-leverage ratio, that is, $\left(D_{i t}+W_{i t}\right) / W_{i t}$. Consistent with Brownlees and Engle (2017), $k$ is set to 8\%, while severe market decline implies a 40\% semiannual shrinkage in global stock market indices (e.g., MSCI world index). Based on Eq. (2), larger financial institutions, higher values of LRMES, and higher leverage involve an increase in SRISK.

The SRISK measure fares better than the alternative systemic risk measures, such as the marginal expected shortfall (MES) by Acharya et al. (2017) or delta conditional value-at-risk $(\triangle \mathrm{CoVaR})$ by Adrian and Brunnermeier (2016), in several empirical horse races conducted to test for the relative consistency and informativeness of such measures (e.g., Dissem and Lobez 2020; Grundke and Tuchsherer 2019; Stolbov and Shchepeleva 2018). Particularly, we prefer the SRISK measure as a systemic risk indicator, as it builds on both balance sheet and market data, thereby reflecting market conditions and managerial decisions by financial institutions (Kamani, 2019). ${ }^{4}$

Positive SRISK values are aggregated across financial institutions to build a nationwide measure. Importantly, when computing the nationwide SRISK, the contribution of institutions that exhibit capital surpluses, that is, negative capital shortfalls, is ignored because such excess capital is not easily mobilized through mergers or loans during crises. Thus, simply netting positive and negative values of SRISK across financial institutions is not feasible.

Similarly, summing up such national indicators yields the global SRISK (Fig. 3). This measure is computed on the basis of nationwide metrics for 73 countries, which are borrowed from the Volatility Laboratory at New York University. ${ }^{5}$ Table 6 of the "Appendix" lists the countries and regions. Figure 3 shows that during the observation period, there are two significant episodes of systemic risk buildup: since autumn 2007 until early 2009 and during the European financial crisis (mid-2011 to mid-2013).

World industrial production (WIP) index is a seasonally adjusted weighted index based on industrial production in 85 countries, which account for about $97 \%$ of global industrial output. Table 7 of the "Appendix" lists the countries and regions. The index

\footnotetext{
${ }^{4}$ However, our focus on SRISK does not rule out that alternative systemic risk measures can be of significant use for other research goals. For instance, such goals may comprise capturing the connectedness of financial institutions through network analysis (Hu et al. 2015) and machine learning techniques (Kou et al. 2014, 2019), assessing the contribution of individual entities to the overall stress or disentangling firm-specific factors, which underlie the systemic risk measures (e.g., Zeb and Rashid 2019). For a detailed survey of the recent literature on systemic risk measurement and the taxonomy of measures (see, e.g., Benoit et al. 2017; Silva et al. 2017).

5 See https://vlab.stern.nyu.edu/.
} 

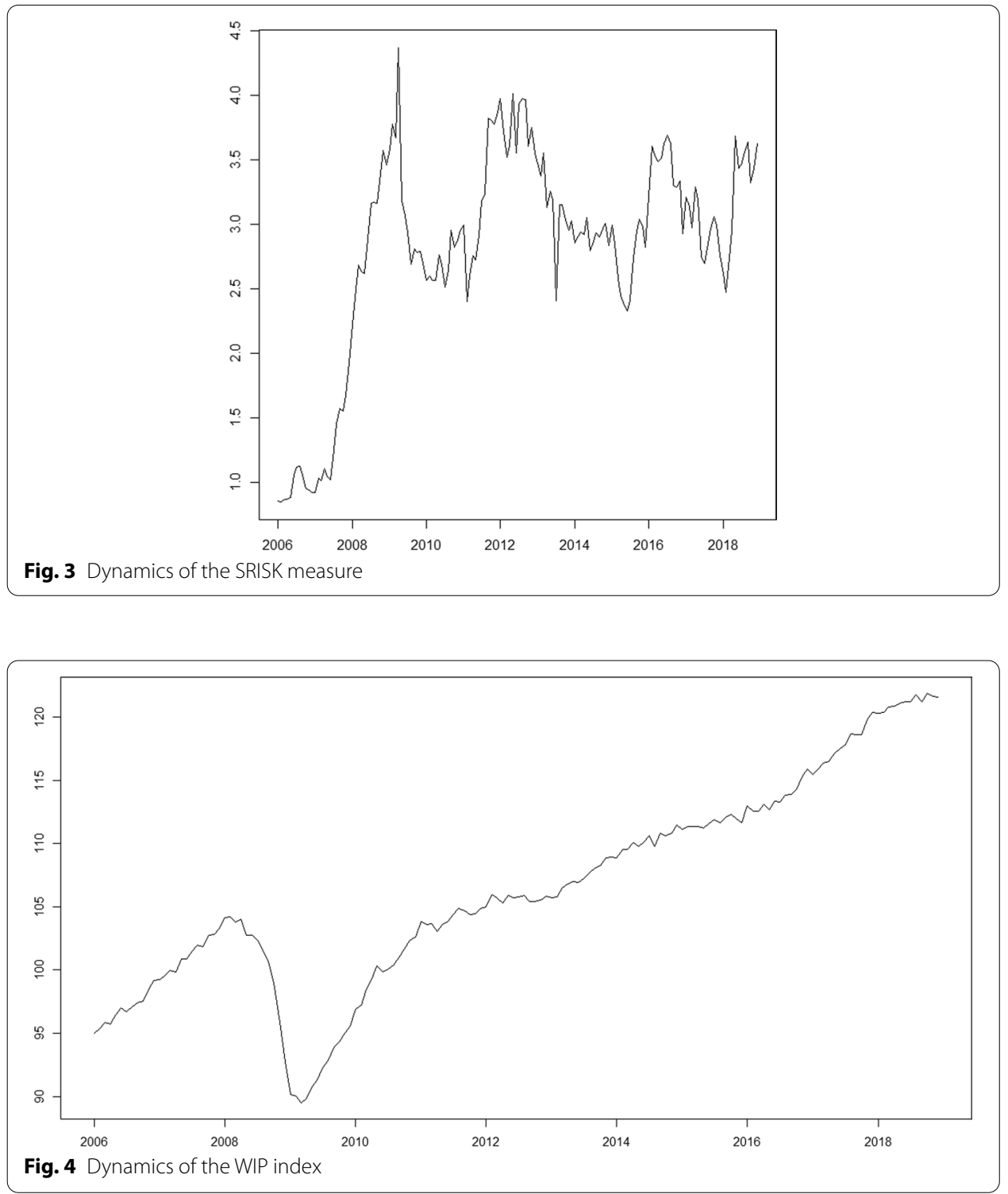

is borrowed from the CPB Netherlands Bureau for Economic Policy Analysis. ${ }^{6}$ Its base year is 2010. Figure 4 reveals the substantial world output loss associated with the GFC and the return to a slower growth trajectory in the post-crisis period.

Table 1 reports the descriptive statistics for all the data series.

\section{Methodology}

\section{Baseline approach ${ }^{7}$}

We use the smooth local projections by Barnichon and Brownlees (2019), who extended the methodology first proposed by Jordá (2005). Local projections (LPs)

\footnotetext{
${ }^{6}$ See https://www.cpb.nl/en/worldtrademonitor.

7 This section largely builds on the original description of the local projections method by Barnichon and Brownlees (2019), and the mathematical notation is borrowed from Stolbov and Shchepeleva (2020).
} 
Table 1 Descriptive statistics of the data

\begin{tabular}{lllll}
\hline & MP & IMAPP & WIP & SRISK \\
\hline Mean & -1.68 & 0.07 & 106.36 & 2.81 \\
Median & -3.30 & 0.04 & 105.70 & 2.95 \\
Maximum & 9.98 & 1.33 & 121.87 & 4.37 \\
Minimum & -9.98 & -0.12 & 89.48 & 0.85 \\
Std. Dev & 5.14 & 0.15 & 8.19 & 0.83 \\
Skewness & 0.32 & 5.99 & 0.08 & -1.04 \\
Kurtosis & 2.16 & 43.52 & 2.32 & 3.42 \\
Jarque-Bera & 7.30 & 1603.75 & 3.17 & 29.08 \\
Probability & 0.03 & 0.00 & 0.20 & 0.00 \\
Observations & 54 & 134 & 85 & 73 \\
\hline
\end{tabular}

enable estimation of impulse responses without specifying and estimating the underlying multivariate dynamic system using VAR. They are more flexible than the VAR models, as this technique better handles data nonlinearity and appears robust to model misspecification. The smooth LPs share these strong points of the standard LP, overcoming its major drawback, that is, a large variability of the impulse response estimator.

Let $x_{t}, y_{t}$, and $z_{i t}$ for $i=1, \ldots, p$ be stationary time series. We also assume that the set of variable $z_{i t}$ may include lagged values of $x_{t}$ and $y_{t}$. We estimate the dynamic multiplier of $y_{t+h}$ with respect to a change in $x_{t}$ for some steps ahead $h$, keeping all other variables constant.

According to Jordá (2005), this multiplier can be recovered from the set of regression coefficients $\beta_{(h)}$ associated with the $h$-step-ahead predictive regressions in the form:

$$
y_{t+h}=\alpha_{(h)}+\beta_{(h)} x_{t}+\sum_{i=1}^{p} \gamma_{i(h)} z_{i t}+u_{(h) t+h},
$$

where $u_{(h) t+h}$ is a prediction error term. The set of regressions in (3) is named LPs. In this framework, the dynamic multiplier $\beta_{(h)}$ can be estimated by running $h+1$ Ordinary Least Squares (OLS) regressions. Given that the multiplier in (3) is expensively parametrized, the OLS estimation may suffer from excessive variability.

Barnichon and Brownlees (2019) apply the LP estimation methodology based on B-splines, naming it smooth LPs, to overcome this issue. B-splines are a basis of hump-shaped functions indexed by a set of knots and composed of $q+1$ polynomial pieces of order $q$. In this setting, the dynamic multiplier $\beta_{(h)}$ can be approximated using a linear B-splines basis function expansion in the forecast horizon $h$ :

$$
\beta_{(h)}=\sum_{k=1}^{K} b_{k} B_{k}(h),
$$


where $B_{k}$ is a set of B-spline basis functions and $b_{k}$ is a set of scalar parameters for each $k=1, \ldots, K$. Adopting the analogous approach to $\alpha_{(h)}$ and $\gamma_{i(h)}$ terms, the following approximation for (3) is obtained:

$$
y_{t+h} \approx \sum_{k=1}^{K} a_{k} B_{k}(h)+\sum_{k=1}^{K} b_{k} B_{k}(h) x_{t}+\sum_{i=1}^{p} \sum_{k=1}^{K} c_{i k} B_{k}(h) z_{i t}+u_{(h) t+h}
$$

Model (5) retains linearity with respect to the parameters and can be considered a linear regression, which is further subject to a generalized ridge estimation to obtain the values of the dynamic multiplier $\beta_{(h)}$, corresponding to impulse responses and their confidence bands. ${ }^{8}$

Before applying the smooth LP, we ensure data stationarity by examining whether our data series predominantly follow the $\mathrm{I}(0)$ pattern in a battery of unit root tests. Our set includes the ADF, DF-GLS, Phillips-Perron, KPSS, and Elliott-Rothenberg Stock PointOptimal unit root tests. Besides, we assume that in our four-variable setting, all variables are endogenous and no additional controls apply. Using the smooth LP, the generalized impulse response functions are computed for 12 periods. When deriving these impulse responses, we determine the number of lags on the basis of the Bayesian information criteria and ensure the absence of a serial correlation.

\section{Extensions}

We extend our baseline exercise in two ways. First, we decompose systemic risk into low and high regimes, assuming that macroprudential and/or monetary policy relationships with SRISK under these regimes may differ. Besides, low- and high-risk environments may have distinct effects on real economic activity, as documented by Danielsson et al. (2020). To identify the two regimes, we estimate the trend of SRISK, $\widehat{\tau_{t}}(\lambda)$, using the onesided HP filter with a smoothing factor $\lambda$, which quantifies the deviation of the actual SRISK values from the trend. As recommended for monthly data in the conventional version of the HP filter (Hodrick and Prescott 1997), $\lambda$ is set 14,400.

$$
\widehat{\tau_{t}}(\lambda)=\min _{\left\{\tau_{t}(\lambda)\right\}_{t=1}^{T}} \sum_{t=1}^{T}\left[\operatorname{SRISK} K_{t}-\tau_{t}(\lambda)\right]^{2}+\lambda \sum_{t=2}^{T-1}\left\{\left[\tau_{t+1}(\lambda)-\tau_{t}(\lambda)\right]-\left[\tau_{t}(\lambda)-\tau_{t-1}(\lambda)\right]\right\}^{2},
$$

where $T$ is the number of observations.

We obtain low and high SRISK (SRISK_LOW, SRISK_HIGH $_{t}$ ) as actual SRISK values below and above the prevailing trend, $\widehat{\tau_{t}}$ :

$$
\begin{aligned}
& \text { SRISK_HIGH }= \begin{cases}\text { SRISK }_{t}-\widehat{\tau_{t}}, & \text { if } \text { SRISK }_{t} \geq \widehat{\tau_{t}} \\
0 & \text { otherwise },\end{cases} \\
& \text { SRISK_LOW }
\end{aligned}
$$

\footnotetext{
${ }^{8}$ We exploit an R code provided by Barnichon and Brownlees (2019) to derive the impulse response functions, previously adjusting it for our four-variable setting. See https://dataverse.harvard.edu/dataset.xhtml?persistentId=doi:10. 7910/DVN/8KQJBJ.
} 


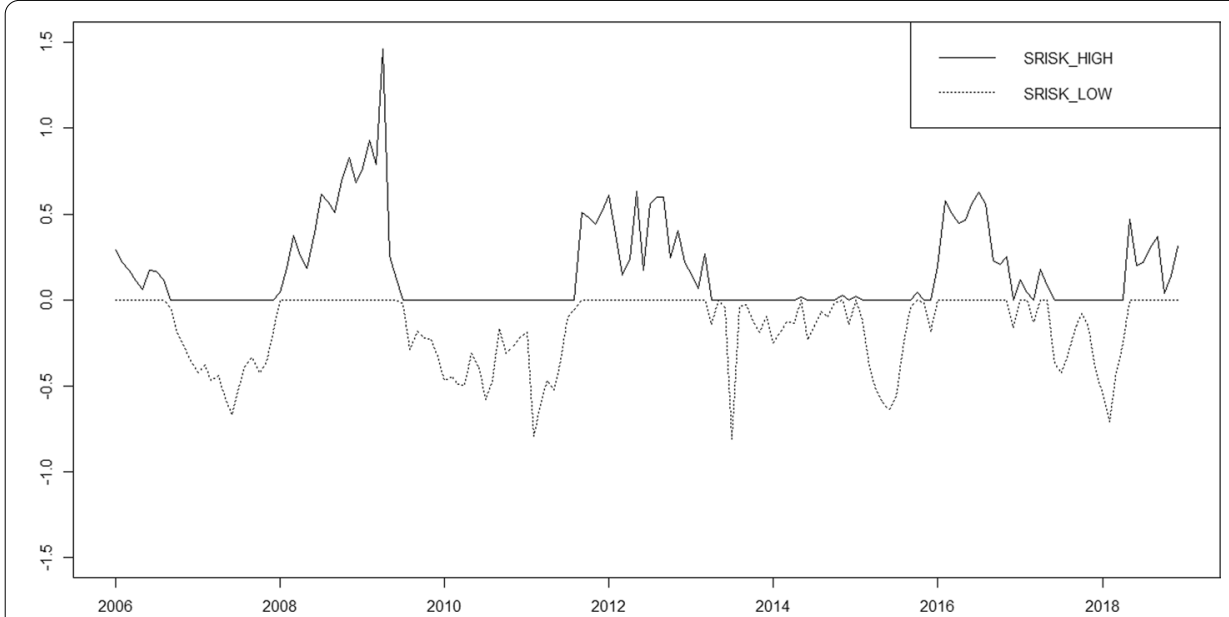

Fig. 5 Low and high regimes of SRISK

Table 2 Unit root tests results for the MP, SRISK, IMAPP, and WIP variables

\begin{tabular}{lllll}
\hline & MP & SRISK & IMAPP & WIP \\
\hline ADF & $\mid(0)^{* * *}$ & $\mid(1)^{* * *}$ & $\mid(1)^{* * *}$ & $\mid(0)^{* * *}$ \\
DF GLS & $\mid(1)^{* * *}$ & $\mid(1)^{* * *}$ & $\mid(1)^{* * *}$ & $\mid(0)^{* * *}$ \\
Phillips-Perron & $\mid(0)^{* *}$ & $\mid(0)^{*}$ & $\mid(0)^{* * *}$ & $\mid(1)^{* * *}$ \\
KPSS & $\mid(0)^{* * *}$ & $\mid(0)^{* *}$ & $\mid(0)^{* * *}$ & $\mid(0)^{* * *}$ \\
Elliott-Rothenberg-Stock & $\mid(0)^{* * *}$ & $\mid(0)^{* * *}$ & $\mid(0)^{* * *}$ & $\mid(1)^{* * *}$ \\
\hline
\end{tabular}

*** significant at $1 \%,{ }^{* *}$ significant at $5 \%,{ }^{*}$ significant at $10 \%$

Figure 5 illustrates the two regimes. Intuitively, a high-risk regime is observed during the GFC in the late 2007 to 2009 and during the most acute phase of the European financial crisis in the late 2011-2013.

Our second extension involves dividing the index of global macroprudential policy activism into two sub-indices. The first sub-index covers the instruments from the IMF iMaPP database, which directly affect borrowers, that is, limits to the loan-tovalue (LTV) and the debt-service-to-income (DSTI) ratios. The share of LTV and DSTI ratios totals $11 \%$ of all macroprudential measures applied globally during the observation period. The other sub-index tracks the aggregate dynamics of financial institution-targeted macroprudential measures, which are actually the remaining 15 instruments in the IMF iMaPP database, such as capital requirements, reserve requirements, caps on growth, or the volume of aggregate credit. We, then, apply the smooth LP to our four-variable system, including each sub-index separately. By distinguishing between the borrower- and financial institution-targeted components of the index, we hypothesize that these measures may have a unique impact on systemic risk or industrial production, thereby changing the relationships identified in the baseline estimation. Recent empirical studies have motivated such conjecture, 


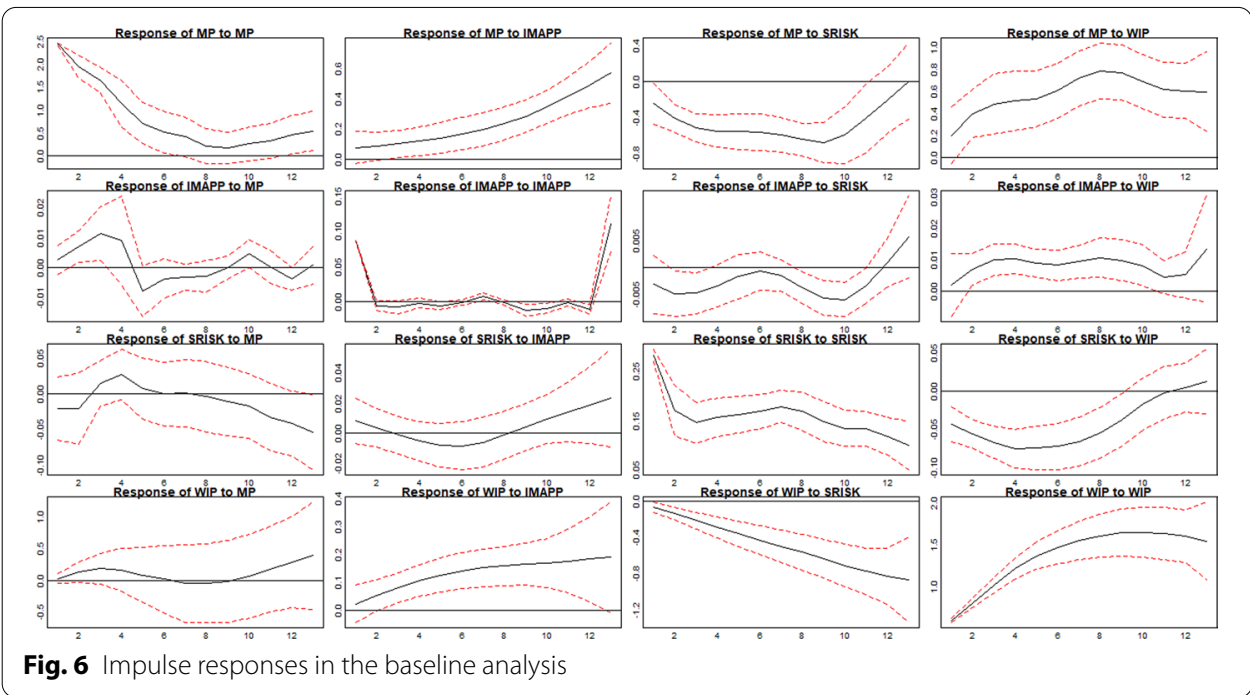

finding that borrower-targeted measures are more effective in mitigating financial instability than policies targeted at banks (e.g., Ayyagari et al. 2018), since differences in country-level financial regulation and supervision in case of financial institution-targeted measures may lead to regulatory arbitrage.

\section{Results and discussion}

\section{Baseline results}

We first report that all data series in levels predominantly exhibit the I(0) pattern. Thus, the smooth LP can be applied (Table 2).

Figure 6 shows the results of our baseline analysis.

We start by documenting an inverse bidirectional relationship between SRISK and industrial production. The WIP index exhibits a yawning decline in response to SRISK. Such adverse impact of systemic risk on real economic activity resonates with the existing literature (Brownlees and Engle 2017; Engle et al. 2015; Giglio et al. 2016; Kabundi and De Simone 2020). Increases in the WIP index reduce SRISK, but this effect is statistically significant in the short run (up to nine periods).

Surprisingly, no direct effect of global macroprudential and monetary policies on SRISK is found. However, in case of global macroprudential policy, an indirect effect is exerted through its impact on industrial production. Indeed, an increase in the $i M a P P$ index appears to spur the WIP index. The finding that macroprudential tightening can be pro-growth is intensely debated in the empirical literature. Against this backdrop, our result is consistent with the conclusions by Boar et al. (2017) and by Andries and Melnic (2019), while contrasting with the findings by Belkhir et al. (2020) and Madeira (2020). Yet, none of these studies assesses the effects of macroprudential policy on real economic activity from the global perspective, focusing on panel data.

The positive relationship running from the $i M a P P$ to WIP index suggests that global macroprudential policy is countercyclical. In turn, the WIP index appears to increase the $i M a P P$ as well. The result indicates that the precautionary macroprudential policy measures are undertaken before a decline in global real economic activity, which additionally 


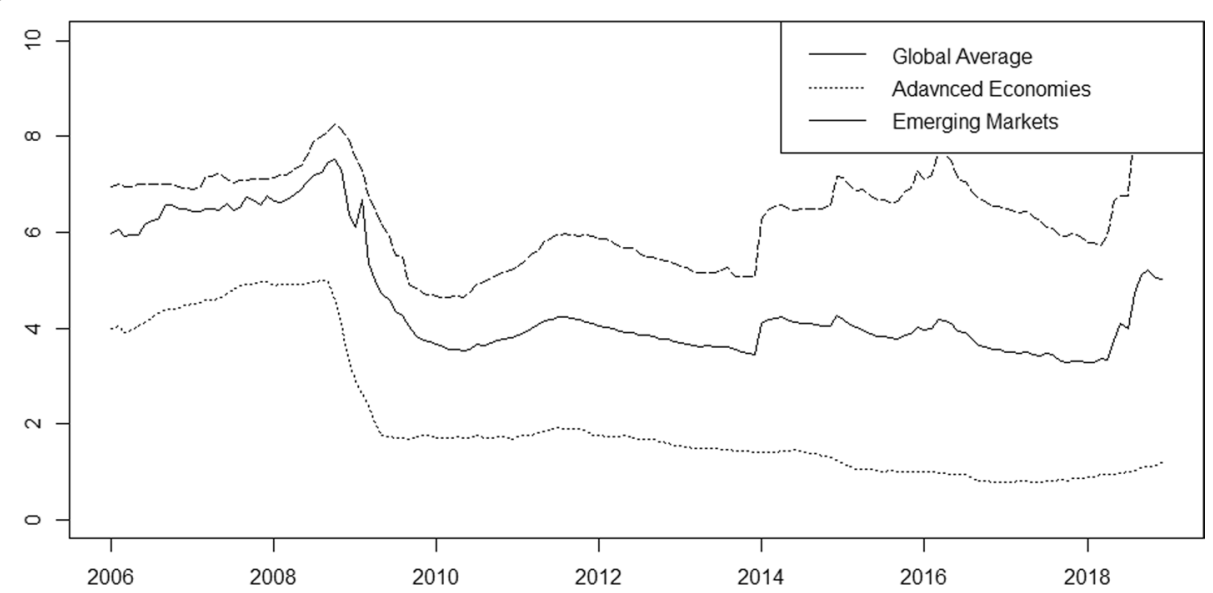

Fig. 7 Dynamics of average policy interest rates across the world, advanced and emerging markets, January 2006-December 2018. Source: BIS data

corroborates the countercyclical nature of the global macroprudential regulation. The relationship running from SRISK to the $i M a P P$ index has weak signs of pro-cyclicality. It is statistically insignificant on impact and further, up to eight periods, turning significant and negative only in the longer run. Thus, the evidence suggests that persistently increasing systemic risk results in global macroprudential policy loosening.

Monetary policy is driven by the changes in industrial production and systemic risk without producing any effect on them. In case of its response to the WIP index, the motion is countercyclical: higher levels of industrial production involve monetary policy tightening. In contrast, it exhibits pro-cyclicality with respect to SRISK.

Overall, our findings indicate that global macroprudential policy has a more pronounced effect on both systemic risk and real economic activity than monetary intervention. We also find that macroprudential policy leads the monetary one. Such relative superiority of macroprudential policy can arise from the low-interest-rate environment, which entrenched after the GFC and substantially narrowed the scope of monetary policy. Such decline in policy rates occurred, on average, not only in advanced economies, but also in emerging markets, thereby shaping the global trend (Fig. 7).

Our result comports with the conclusions by Farhi and Werning (2016), who proposed a theory of unified monetary and macroprudential policies in economies with nominal rigidities and constraints on monetary intervention, such as the zero lower bound (ZLB). They argued that in such a framework, monetary policy creates an aggregate demand externality, which undermines its efficacy in achieving macroeconomic stabilization. This failure of monetary policy can be offset by macroprudential intervention. Korinek and Simsek (2016) reported close theoretical results, emphasizing the efficacy of macroprudential policy in mitigating liquidity traps. Similarly, Van der Ghote (2020) underscored the positive impact of macroprudential policy on real interest rates, which can rescue the economy from a liquidity trap. Rubio and Yao (2020) confirmed the relative superiority of macroprudential policy by calibrating a DSGE model with macroprudential intervention in terms of low-interest-rate environment. Another calibration exercise 


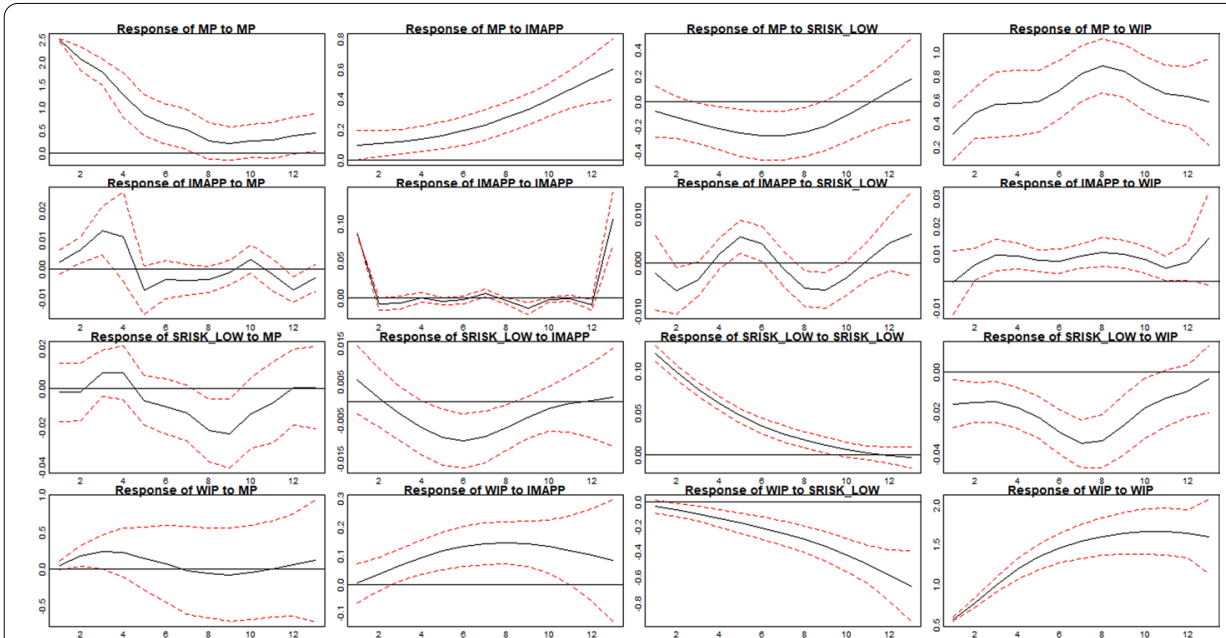

(a)
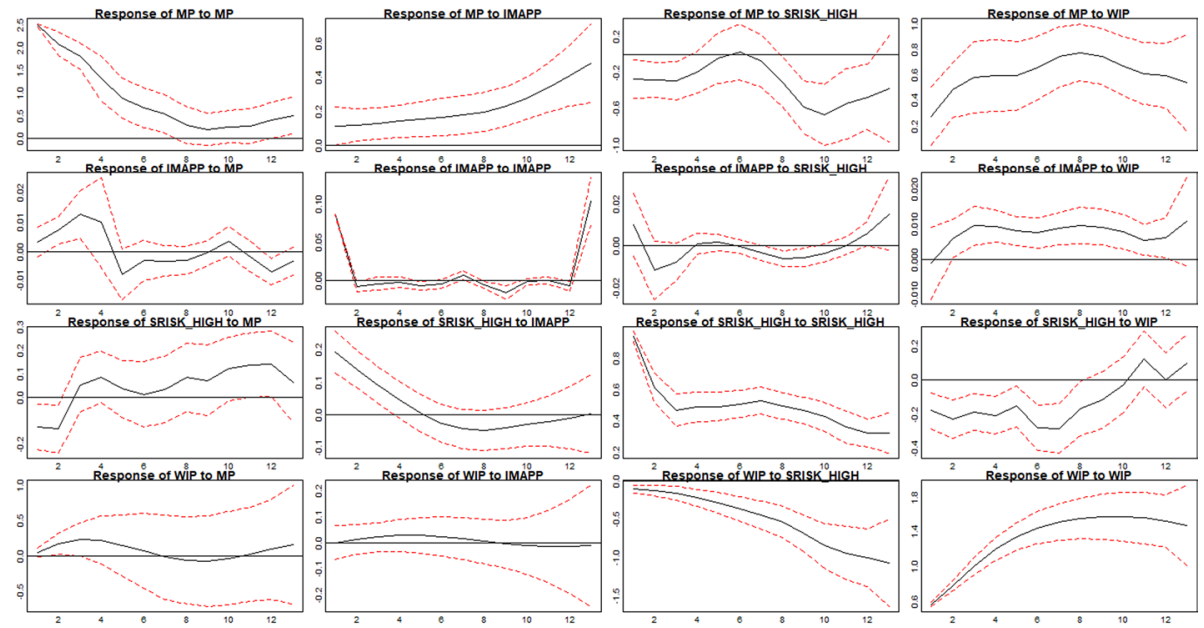

(b)

Fig. 8 Impulse responses in terms of $\mathbf{a}$ low-risk and $\mathbf{b}$ high-risk regimes

by Jerger and Körner (2018) yielded the same result. Moreover, in a medium-size DSGE model, Bonciani et al. (2021) found that the implementation of a macroprudential policy per se reduces the odds of the monetary policy rate reaching the ZLB. Besides, they argued that macroprudential policy can enhance growth, as it mitigates productivity slowdown, which is often overlooked as a long-term consequence of financial crises.

Our results are also consistent with two growing strands of empirical studies. The first strand shows that although tight macroprudential policy may have adverse short-run effects on real activity, it eventually results in net gains by reducing tail risks to future output growth (e.g., Brandao-Marques et al. 2020; Franta and Gambacorta 2020; Galán 2020). The other strand supporting our results argues that monetary policy should play an auxiliary role to make macroprudential intervention more effective in safeguarding financial stability (e.g., Gambacorta and Murcia 2020; Lozano-Vivas and Pasiouras 2019; Revelo et al. 2020). 


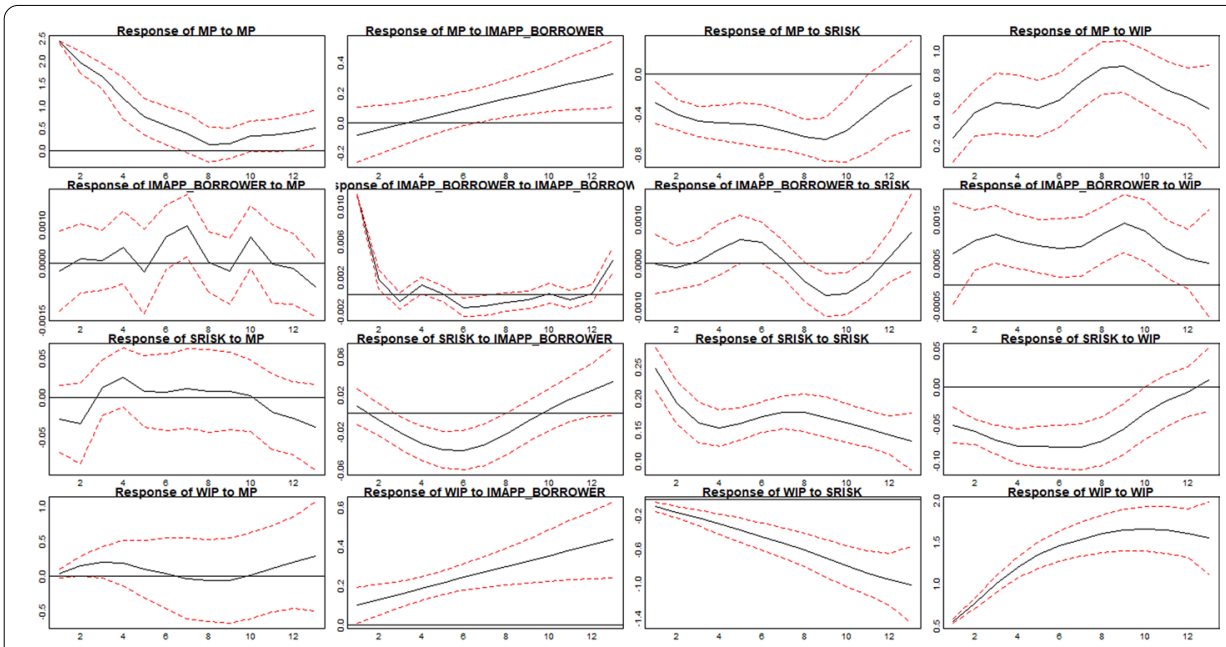

(a)
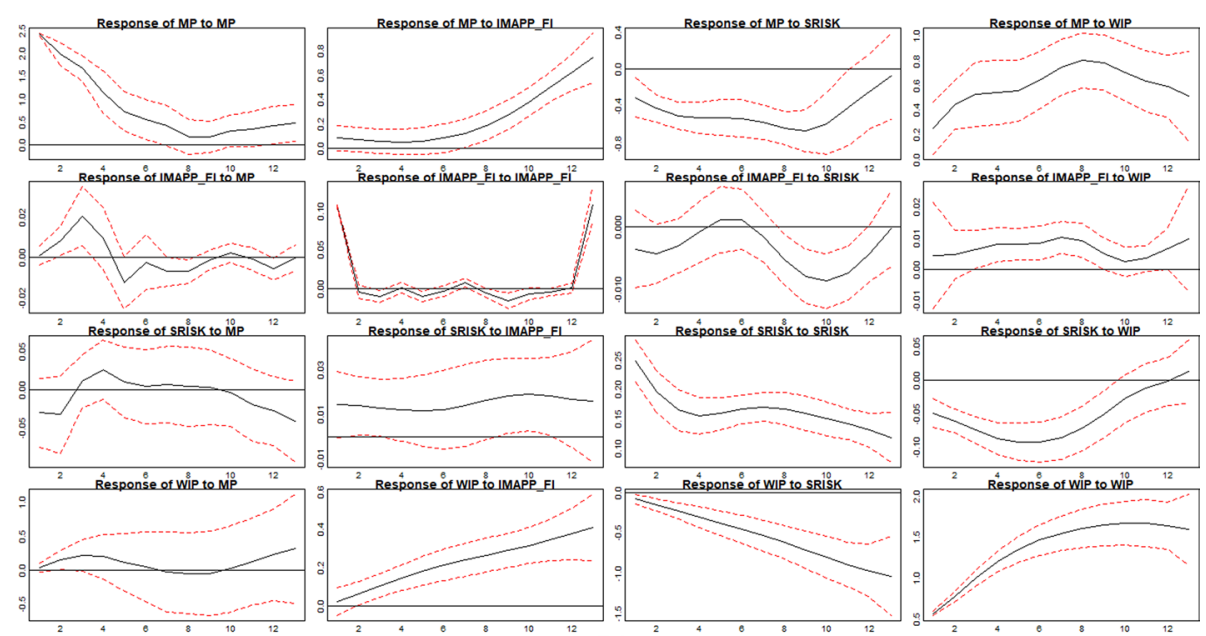

(b)

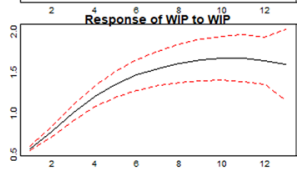
sub-indices

\section{Results of the extensions}

Decomposing SRISK into low and high regimes does not alter the major baseline conclusion regarding the pivotal role of global macroprudential policy for the monetary policy. ${ }^{9}$ We also document countercyclical patterns in the response of macroprudential and monetary policies to global industrial production. However, certain responses (e.g., SRISK to the WIP index and vice versa) differ by their magnitude, depending on a lowor high-risk regime. These reactions are stronger in the high-risk environment SRISK and the WIP index. Besides, the pro-growth effect of $i M a P P$ index is only observed in the low-risk environment, disappearing in the high-risk one. The latter finding suggests

\footnotetext{
${ }^{9}$ Before extending the baseline estimations, we also apply our battery of unit root tests to the modified data series. The same procedure applies to the variables used in the robustness check. See the results of unit root tests in the "Appendix", Table 8 .
} 
that preemptive macroprudential policy is beneficial and wealth-enhancing when systemic risk has not built up yet. Figure $8 \mathrm{a}$, b shows the corresponding impulse responses.

Splitting the $i M a P P$ index into borrower- and financial institution-targeted sub-indices also retains most of the baseline relationships (Fig. 9a, b). In this extension, we find some evidence that macroprudential measures aimed at borrowers decrease systemic risk more efficiently than those targeted at financial institutions. Nonetheless, the two types of measures are complementary in fostering global industrial production.

Overall, our additional exercises yield the results that are qualitatively similar to the baseline estimation regarding the relative superiority of macroprudential policy. In the modified frameworks, it still leads the monetary policy, demonstrating counter-cyclicality regarding industrial production. Global monetary policy has no effect on SRISK and industrial production, but adjusts to them in a pro-cyclical manner in case of systemic risk and countercyclically with respect to industrial production.

\section{Robustness check}

We conduct a twofold robustness check, building on alternative measures of global systemic stress and real economic activity.

Considering that SRISK appears to outperform its main competitors, primarily MES and $\triangle \mathrm{CoVaR}$, in various empirical horse races in terms of consistency and informativeness, we do not focus on these systemic risk metrics to test the validity of our baseline results. Instead, we replace SRISK with the OFR financial stress index proposed by Monin (2019) and used by the US Financial Stability Oversight Council to monitor global financial stability. ${ }^{10}$ It co-moves with the SRISK measure, but not in a one-toone manner: their correlation ratio is 0.4 , and it is significant at the $1 \%$ level. Although the OFR financial stress index is not formally categorized as a systemic risk measure, it possesses its attributes. Namely, it also aims to detect when the global financial system functioning is impaired by covering the dynamics of key financial markets and considering the vulnerability of different countries, both advanced and emerging market economies. ${ }^{11}$ The index is available on a high-frequency basis and helps predict decreases in the real economic activity (Monin 2019). Our baseline methodology and its two extensions fully apply to the robustness check, based on the OFR financial stress index. The corresponding impulse responses are reported in the "Appendix" (Figs. 10, 11, 12).

The OFR financial stress index is found to adversely impact the WIP index; however, unlike the baseline estimation involving SRISK, there is no feedback from industrial production to the global financial stress. When the OFR financial stress index is decomposed into low and high components, all relationships exhibit the same directions as in the baseline estimation involving SRISK. When considering the two sub-indices of global macroprudential policy activism, we find that the borrower-targeted measures produce a statistically significant dampening effect on the global financial stress, whereas financial institution-targeted measures do not mitigate it.

\footnotetext{
${ }^{10}$ However, we perform estimations based on these metrics as well. The results are consistent with those reported in the study and are available upon request from the authors.

11 It tracks the developments in the credit market, equity valuation, funding costs, volatility, and safe assets. See https:// www.financialresearch.gov/financial-stress-index/ for a detailed description.
} 
Considering that the WIP index depends on periodic data revisions, our second robustness exercise uses an alternative proxy of global real economic activity. This measure (PC_REA) builds on the first principal component derived from the shipping costs index (Hamilton 2021) and GECON, a monthly global economic conditions indicator (Baumeister et al. 2020). ${ }^{12}$ Similar to the baseline estimation, PC_REA has bidirectional inverse linkages with SRISK. However, in contrast, we find almost no signs of monetary policy pro-cyclicality with respect to PC_REA. Furthermore, monetary policy tightening favors a rise in SRISK, a significant relationship in the high-risk environment (Figs. 13, $14,15)$.

Despite the minor differences with the baseline estimation, the core findings regarding the superiority of global macroprudential policy over the monetary policy and its countercyclical properties are found to be robust.

\section{Conclusions}

This study deals with the global dimension of macroprudential and monetary policies interacting with each other and with global systemic risk and industrial production from January 2006 to December 2018. The novel smooth LP method is applied to examine the dynamic relationships among these variables.

Our findings legitimize the importance attached to macroprudential policy since the GFC. Globally, macroprudential policy appears to lead the monetary policy. Although we do not find convincing evidence that global macroprudential policy directly mitigates systemic risk, this impact can be channeled through the countercyclical effect of macroprudential intervention on industrial production. Specifically, preemptive macroprudential policy promotes real economic activity, which, in turn, curbs the buildup of systemic risk. We conjecture that the low-interest-rate environment, which entrenched after the GFC and substantially narrowed the scope of monetary policy, accounts for the relative superiority of macroprudential policy. This explanation for our major empirical result resonates well with the recent theoretical works, emphasizing the efficacy of macroprudential policy in mitigating liquidity traps, and with the empirical studies, which argue that, regardless of the possible short-run contractionary effects on real activity, tight macroprudential policy favors the net benefits for the economy by minimizing tail risks to future output growth.

The extension to our baseline analysis, which accounts for different regimes in systemic risk and for borrower- and financial institution-targeted macroprudential measures, and the robustness check, which involves the alternative measures of global systemic stress and real economic activity, do not alter our main findings.

\footnotetext{
12 The measures of global economic activity are intensely debated nowadays. For instance, Hamilton (2021) blames the Kilian index of global economic activity (Kilian 2009, 2019) based on shipping costs for bearing little resemblance to real-world economic dynamics since 2009. To address the problem, he proposes his own version of the Kilian index based on an alternative de-trending procedure. Meanwhile, Baumeister et al. (2020) introduced a comprehensive indicator tracking global economic conditions, GECON, which captures several measures beyond the world industrial production, e.g., energy production and electricity distribution, passenger car registrations, and oil price uncertainty. Baumeister and Guérin (2020) showed that the GECON indicator consistently outperforms competing proxies of global economic activity in forecasting quarterly world GDP, such as world industrial production, global steel production, the Kilian index of global economic activity, and real commodity prices. Against this backdrop, in this study, we employ a composite measure of global real economic activity by deriving the first principal component from two of its most promising proxies: the Hamilton shipping costs index and the GECON indicator. This component accounts for about $60 \%$ of the total variance of these measures.
} 
Our study has certain limitations. Given that our time series are not sufficiently long, we are unable to reliably examine the time-varying nature of the relationships among the four variables. This obstacle will eventually disappear with the future updates of the IMF database on macroprudential policy measures, allowing use of a time-varying VAR or similar techniques. Another promising avenue of research involves application of our methodological approach to the regional rather than global level. It will allow capturing region-specific linkages among macroprudential policy, systemic risk, industrial production, and monetary intervention, which may differ from those revealed on the global level.

\section{Appendix}

See Tables 3, 4, 5, 6, 7, 8 and Figs. 10, 11, 12, 13, 14, 15.

Table 3 The structure of the IMaPP index

\begin{tabular}{ll}
\hline $\begin{array}{l}\text { Borrower-targeted } \\
\text { macroprudential measures }\end{array}$ & Financial institution-targeted measures \\
\hline LTV (Loan-to-value ratio) & CCB (Countercyclical capital buffer) \\
DSTI (Debt-service-to-income ratio) & Conservation (Capital conservation buffer) \\
& Capital (Capital requirements for banks) \\
& LVR (A limit on leverage of banks) \\
& LLP (Loan loss provision) \\
& LCG (Limits on growth or the volume of aggregate credit) \\
& LoanR (Loan limits and prohibitions conditioned on loan characteristics, \\
& bank characteristics, and other factors) \\
& LFC (Limits on foreign currency lending) \\
& Tax (Taxes and levies applied to specified transactions, assets, or liabilities) \\
Liquidity (Measures taken to mitigate systemic liquidity and funding risks) & LTD (Limits to the loan-to-deposit (LTD) ratio and penalties for high LTD \\
ratios) & LFX (Limits on net or gross open foreign exchange (FX) positions, limits on \\
& FX exposures and FX funding, and currency mismatch regulations) \\
RR (Reserve requirements for macroprudential purposes) \\
SIFI (Measures taken to mitigate risks from global and domestic systemically \\
important financial institutions) \\
Other (Macroprudential measures not captured in the above categories, \\
e.g., stress testing, restrictions on profit distribution, and structural meas- \\
ures)
\end{tabular}


Table 4 List of countries and regions covered by the iMaPP index

Albania, Algeria, Angola, Argentina, Armenia, Australia, Austria, Azerbaijan, Bahamas, Bahrain, Bangladesh, Belarus, Belgium, Benin, Bhutan, Bosnia and Herzegovina, Botswana, Brazil, Brunei, Bulgaria, Burkina Faso, Burundi, Cambodia, Canada, Cape Verde, Chile, China, Colombia, Congo Democratic Republic, Costa Rica, Cote d'Ivoire, Croatia, Curacao, Cyprus, Czech Republic, Denmark, Dominican Republic, Ecuador, El Salvador, Estonia, Ethiopia, Fiji, Finland, France, Gambia, Georgia, Germany, Ghana, Greece, Guinea Bissau, Haiti, Honduras, Hong Kong, Hungary, Iceland, India, Indonesia, Ireland, Israel, Italy, Jamaica, Japan, Jordan, Kazakhstan, Kenya, Korea, Kosovo, Kuwait, Kyrgyz Republic, Laos, Latvia, Lebanon, Lesotho, Lithuania, Luxembourg, Macedonia, Malaysia, Mali, Malta, Mauritania, Mauritius, Mexico, Moldova, Mongolia, Montenegro, Morocco, Mozambique, Nepal, Netherlands, New Zealand, Niger, Nigeria, Norway, Oman, Pakistan, Paraguay, Peru, Philippines, Poland, Portugal, Romania, Russia, Saint Kitts And Nevis, Saudi Arabia, Senegal, Serbia, Singapore, Slovak Republic, Slovenia, Solomon Islands, South Africa, Spain, Sri Lanka, Sudan, Sweden, Switzerland, Taiwan Province of China, Tajikistan, Tanzania, Thailand, Timor Leste, Togo, Tonga, Trinidad and Tobago, Tunisia, Turkey, Uganda, Ukraine, United Arab Emirates, United Kingdom, United States, Uruguay, Vietnam, Yemen, Zambia

Table 5 List of countries covered by the CFR global monetary policy tracker

Argentina, Australia, Austria, Bangladesh, Belgium, Brazil, Canada, Czech Republic, Chile, China, Colombia, Cyprus, Denmark, Estonia, Finland, France, Germany, Greece, Hungary, Iceland, India, Indonesia, Ireland, Israel, Italy, Japan, Latvia, Lithuania, Malaysia, Mexico, Netherlands, New Zealand, Nigeria, Norway, Pakistan, Peru, Philippines, Poland, Portugal, Romania, Russia, Slovak Republic, Slovenia, South Africa, South Korea, Spain, Sri Lanka, Sweden, Switzerland, Thailand, Turkey, Ukraine, United Kingdom, United States

Table 6 List of countries and regions which national SRISK measures are used to derive the SRISK global metric

Argentina, Australia, Austria, Bahrain, Belgium, Bermuda, Brazil, Canada, Czech Republic, Chile, China, Colombia, Croatia, Cyprus, Denmark, Egypt, Finland, France, Germany, Greece, Guernsey, Hong Kong, Hungary, Iceland, India, Indonesia, Ireland, Israel, Italy, Japan, Jersey, Jordan, Kazakhstan, Kuwait, Lebanon, Liechtenstein, Luxemburg, Malaysia, Malta, Mauritius, Mexico, Morocco, Netherlands, New Zealand, Nigeria, Norway, Oman, Pakistan, Peru, Philippines, Poland, Portugal, Puerto Rico, Qatar, Romania, Russia, Saudi Arabia, Singapore, Slovak Republic, Slovenia, South Africa, South Korea, Spain, Sri Lanka, Sweden, Switzerland, Taiwan, Thailand, Turkey, Ukraine, United Arab Emirates, United Kingdom, United States, Vietnam

Table 7 List of countries and regions which constitute the WIP index

Algeria, Angola, Argentina, Armenia, Australia, Austria, Belarus, Belgium, Brazil, Canada, Czech Republic, Chile, China, Colombia, Croatia, Cyprus, Denmark, Ecuador, Egypt, Estonia, Finland, France, Gabon, Germany, Greece, Hong Kong, Hungary, Iceland, India, Indonesia, Iran, Iraq, Ireland, Israel, Italy, Japan, Jordan, Kazakhstan, Kuwait, Latvia, Lithuania, Luxemburg, Libya, Macedonia, Malaysia, Malta, Mexico, Montenegro, Morocco, Netherlands, New Zealand, Nigeria, Norway, Oman, Pakistan, Peru, Philippines, Poland, Portugal, Qatar, Romania, Russia, Saudi Arabia, Serbia, Singapore, Syria, Slovak Republic, Slovenia, South Africa, South Korea, Spain, Sri Lanka, Sweden, Switzerland, Taiwan, Thailand, Trinidad \& Tobago, Tunisia, Turkey, Ukraine, United Arab Emirates, United Kingdom, United States, Uruguay, Venezuela 
Table 8 Unit root tests results for the variables used in the extensions and robustness check

\begin{tabular}{|c|c|c|c|c|c|c|c|c|}
\hline & $\begin{array}{l}\text { SRISK } \\
\text { LOW }\end{array}$ & $\begin{array}{l}\text { SRISK } \\
\text { HIGH }\end{array}$ & $\begin{array}{l}\text { IMAPP } \\
\text { BORROWER }\end{array}$ & IMAPP_FI & OFR & OFR_LOW & OFR_HIGH & PC_REA \\
\hline ADF & $\mid(0)^{* * *}$ & $I(0)^{* * *}$ & $I(0)^{* * *}$ & $\mid(1)^{* * *}$ & $I(1)^{* * *}$ & $\mid(1)^{* * *}$ & $I(0)^{* * *}$ & $I(0)^{* * *}$ \\
\hline DF GLS & $\mid(0)^{* * *}$ & $\mid(0)^{* * *}$ & $\mid(0)^{* * *}$ & $\mid(1)^{* * *}$ & $\mid(1)^{* * *}$ & $\mid(1)^{* * *}$ & $\mid(0)^{* * *}$ & $I(0)^{* * *}$ \\
\hline $\begin{array}{l}\text { Phillips- } \\
\text { Perron }\end{array}$ & $\mid(0)^{* * *}$ & $\mid(0)^{* * *}$ & $\mid(0)^{* * *}$ & $\mid(0)^{* * *}$ & $I(0)^{* * *}$ & $\mid(0)^{* * *}$ & $\mid(0)^{* * *}$ & $\mid(0)^{* * *}$ \\
\hline KPSS & $\mid(0)^{* * *}$ & $I(0)^{* * *}$ & $I(0)^{* * *}$ & $\mid(1)^{* * *}$ & $I(0)^{* * *}$ & $\mid(0)^{* * *}$ & $I(0)^{* * *}$ & $\mid(0)^{* * *}$ \\
\hline $\begin{array}{l}\text { Elliott-Roth- } \\
\text { enberg- } \\
\text { Stock }\end{array}$ & $\mid(1)^{* * *}$ & $I(1)^{* * *}$ & $I(1)^{* * *}$ & $\mid(0)^{* * *}$ & $I(0)^{* * *}$ & $\mid(0)^{* * *}$ & $\mid(1)^{* * *}$ & $I(0)^{* * *}$ \\
\hline
\end{tabular}

*,**,***Significant at the $10 \%, 5 \%$, or $1 \%$ level

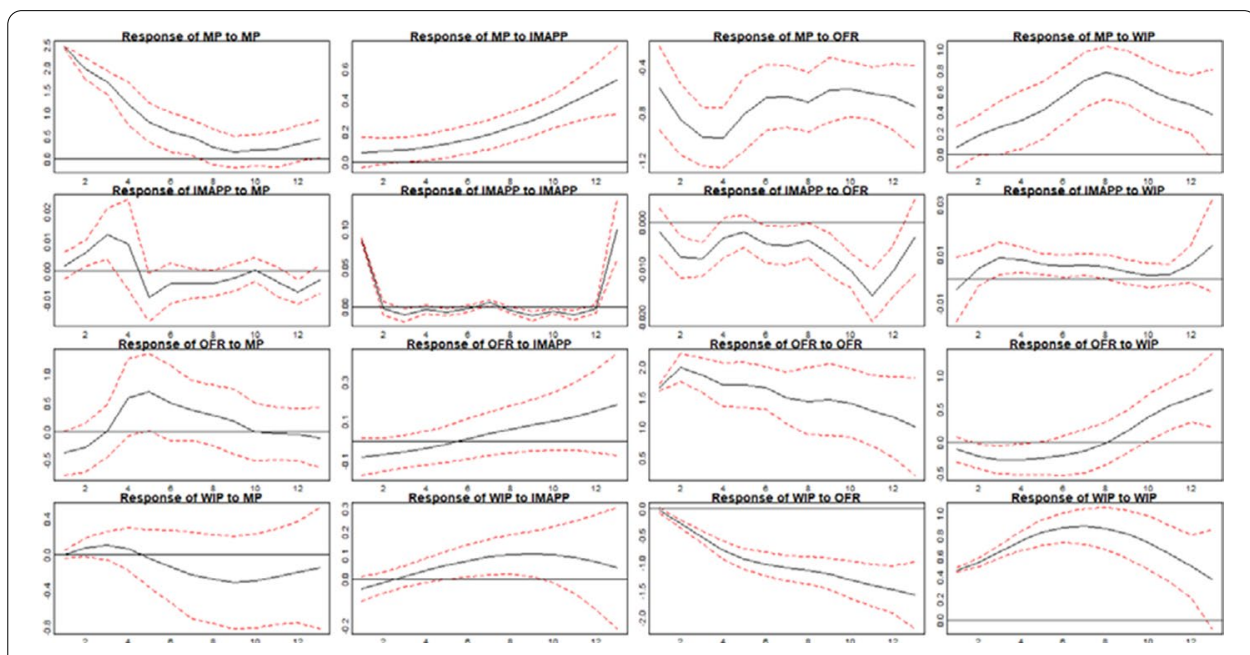

Fig. 10 Impulse responses for the robustness check with the OFR financial stress index 

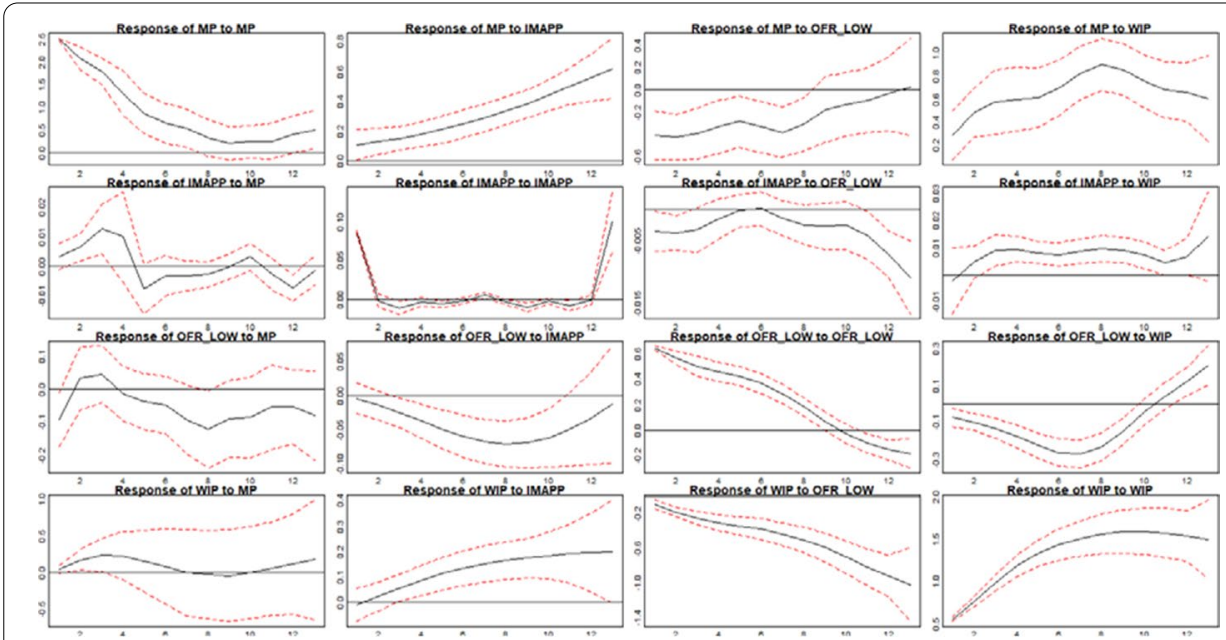

(a)
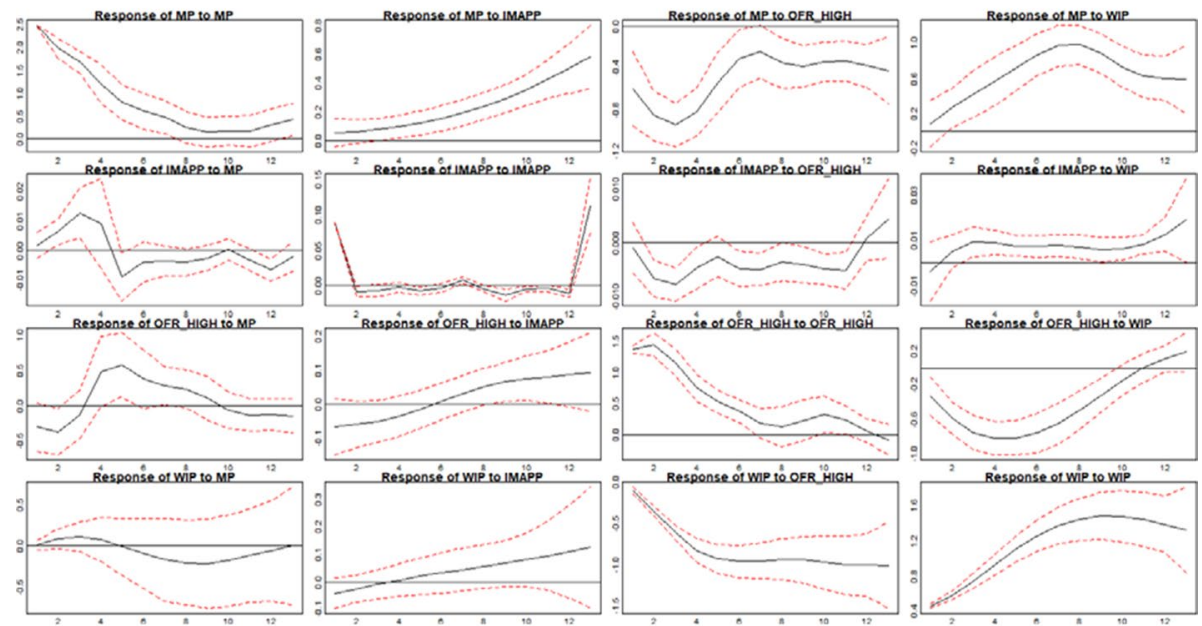

(b)

Fig. 11 Impulse responses for the robustness check with the OFR financial stress index in terms of a low-risk and $\mathbf{b}$ high-risk regimes 


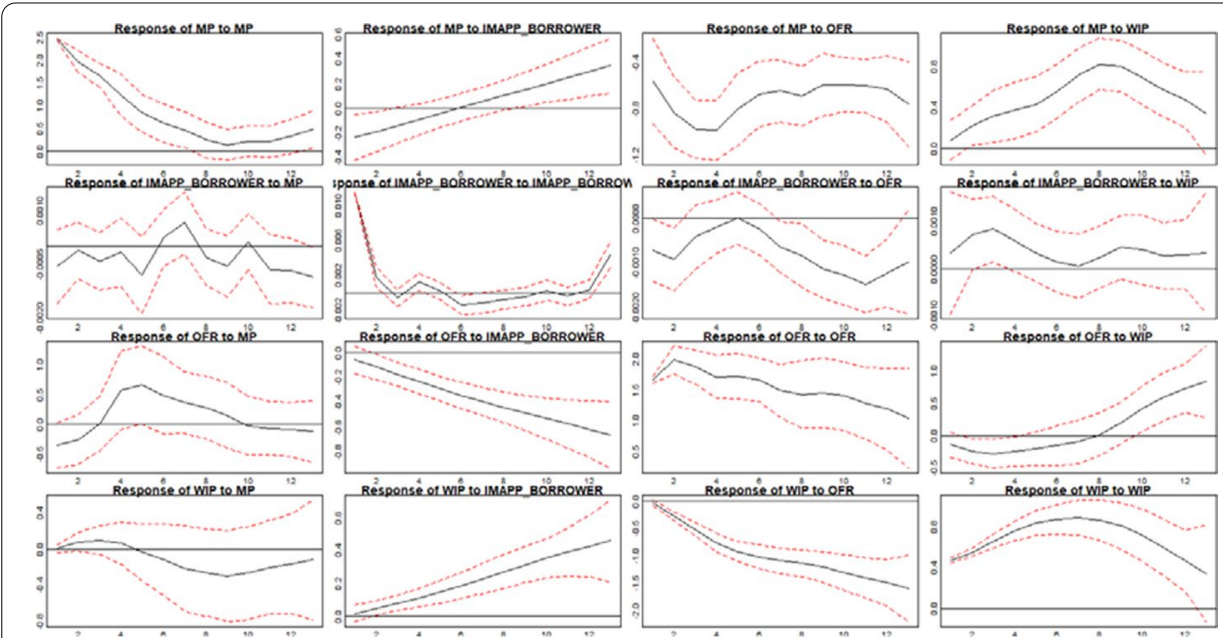

(a)
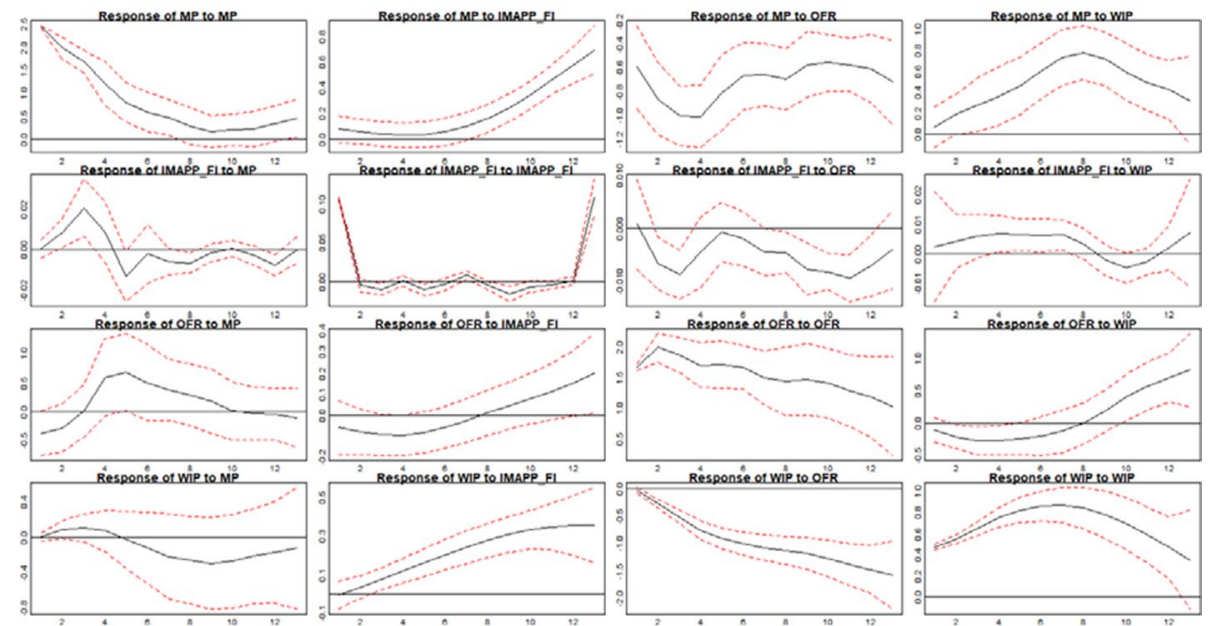

(b)

Fig. 12 Impulse responses for the robustness check with the OFR financial stress index in case of a borrower-targeted and $\mathbf{b}$ financial institution-targeted iMaPP sub-indices 


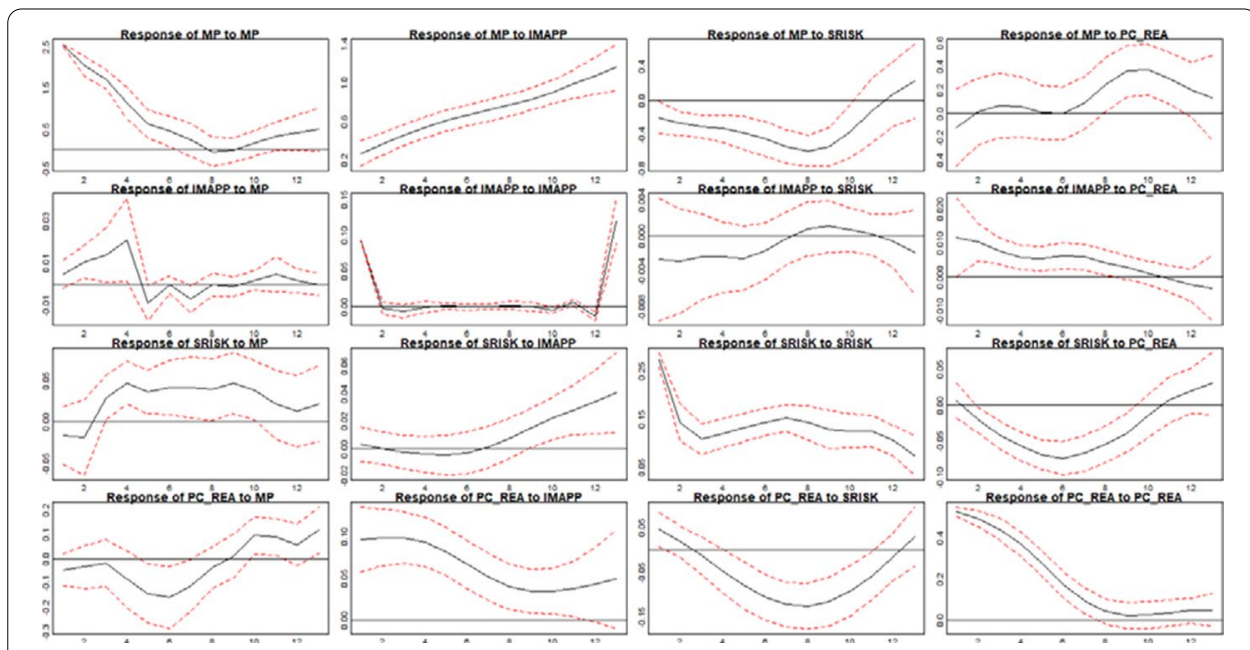

Fig. 13 Impulse responses for the robustness check with the PC_REA index

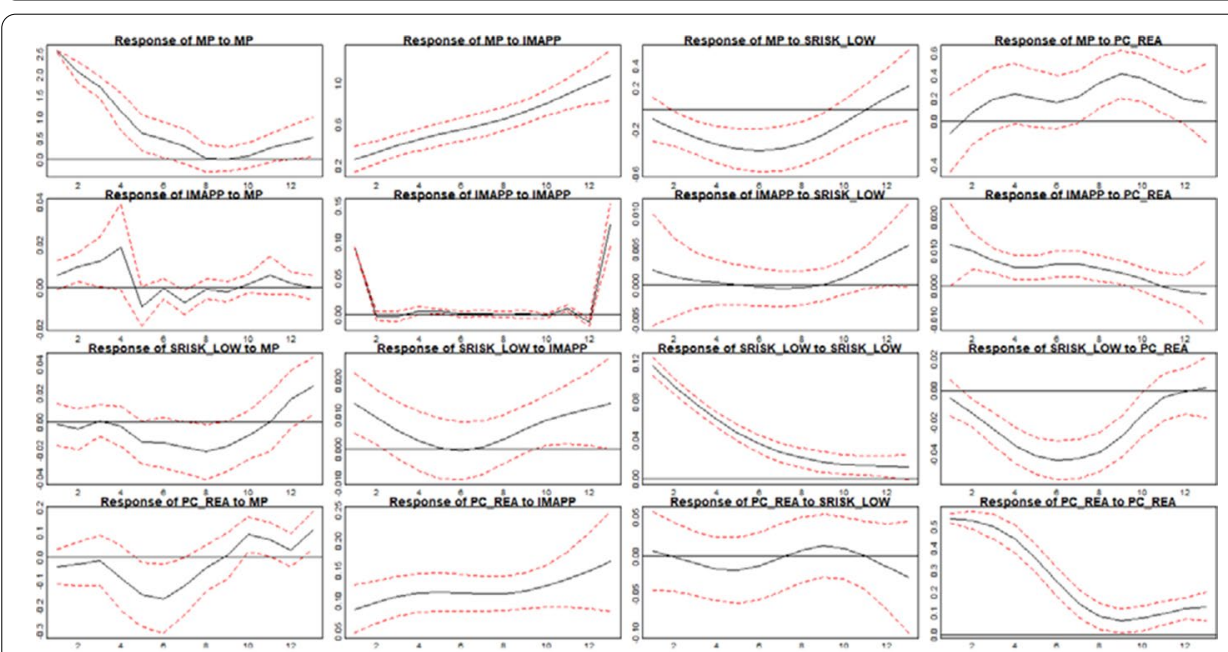

(a)
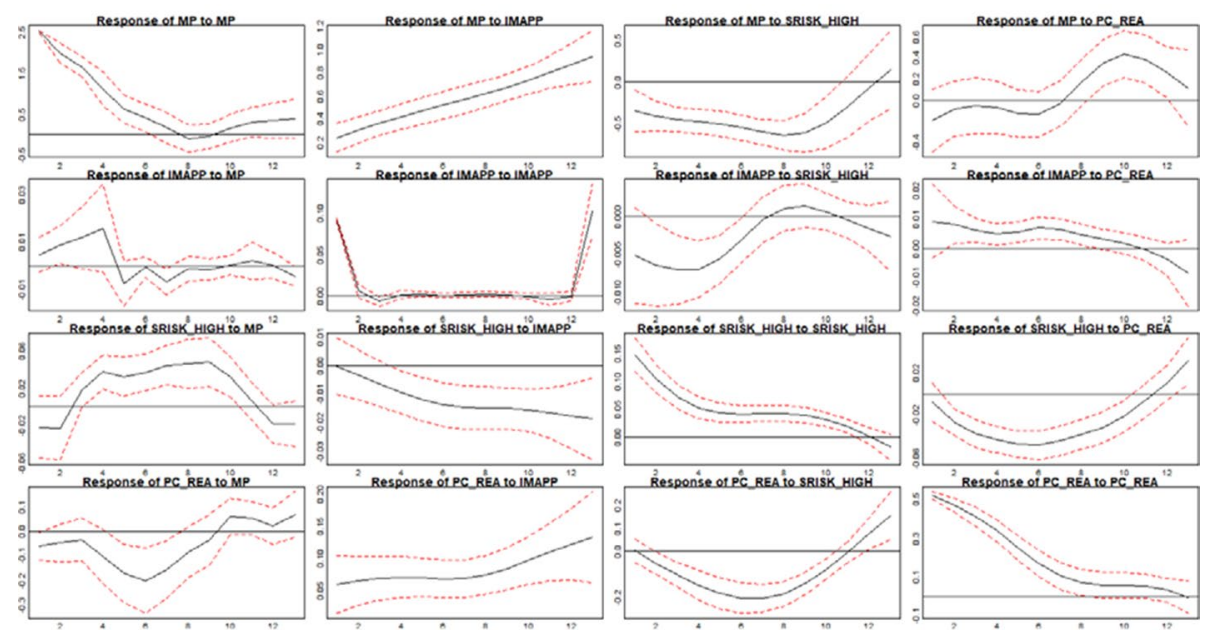

(b)

Fig. 14 Impulse responses for the robustness check with the PC_REA index in terms of $\mathbf{a}$ low-risk and $\mathbf{b}$ high-risk regimes 

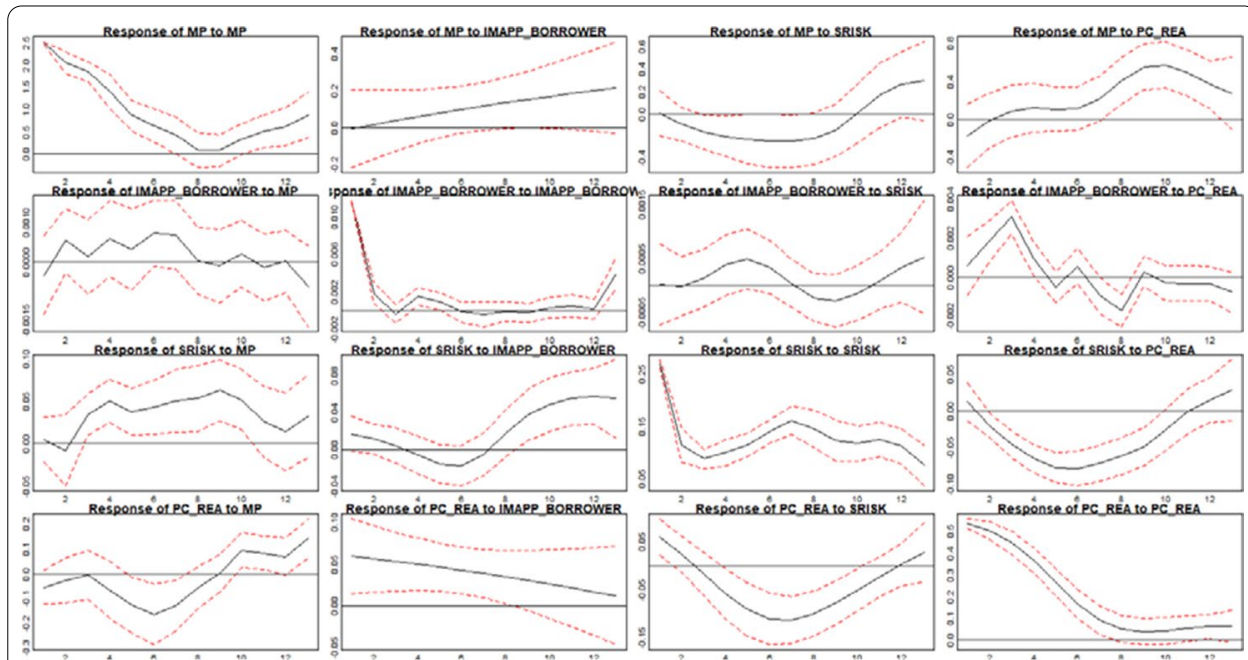

(a)
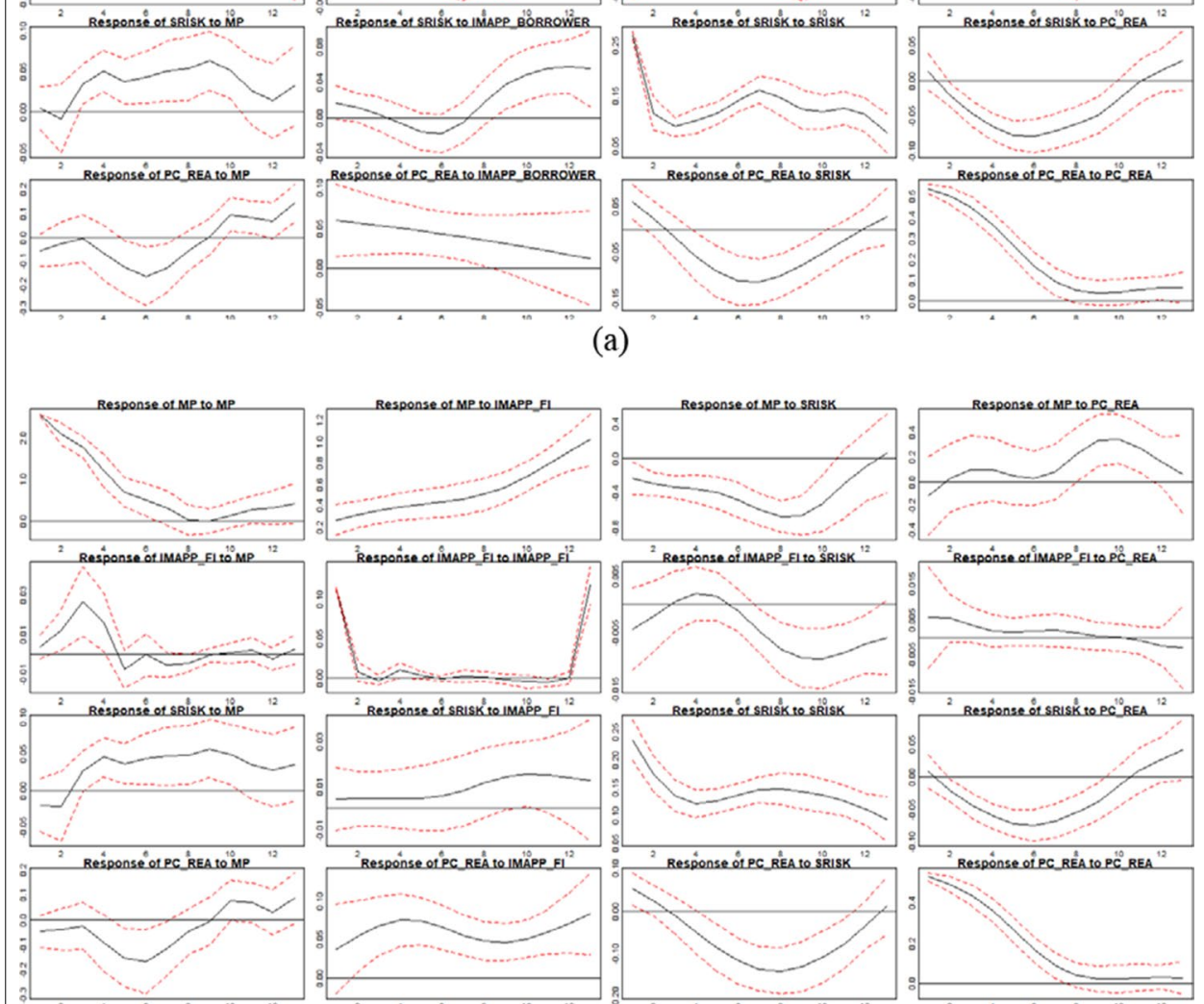

(b)

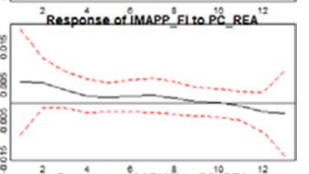

Fig. 15 Impulse responses for the robustness check with the PC_REA index in case of a borrower-targeted and $\mathbf{b}$ financial institution-targeted iMaPP sub-indices

\section{Acknowledgements}

We are grateful to Editor, Gang Kou, and anonymous reviewers whose comments helped improve our manuscript.

\section{Authors' contributions}

MS, MSh, AK: analysis and interpretation of the data as well as preparing the revised manuscript. All authors have read and approved the final version of the revised manuscript.

\section{Authors' information}

Mikhail I. Stolbov, Ph.D. in Economics, is Chair of the Department of Applied Economics at Moscow State Institute of International Relations (MGIMO University). His research areas are financial innovations, digital economics and finance, financial stability and banking. Prof. Stolbov has published in a number of international journals, e.g.Research in International Business and Finance, International Economics, Annals of Finance, Empirical Economics, International Economics and Economic Policy, etc.

Maria A. Shchepeleva, Ph.D. in Economics, is Assistant Professor at the Department of Theoretical Economics at the National Research University Higher School of Economics (Moscow, Russia). Her research interests comprise FinTech, macrofinance, systemic risk and macroprudential policy, machine learning methods. She has a number of publications in international peer reviewed outlets, such as Review of Development Finance, Comparative Economic Studies, Annals of Finance. 
Alexander M. Karminsky, Ph.D. in Economics, is Tenure Professor of Finance and Head of the Research Center of Banking and Risks at the National Research University Higher School of Economics, Moscow (HSE). Alexander Karminsky is on the editorial boards of several scientific journals in Russia and abroad. He is the author of 30+ books and 200+ articles on banking, risk management, econometrics as well as on operational research, IT and controlling.

\section{Funding}

Not applicable.

Availability of data and materials

The dataset compiled and analyzed during the current study are available from the corresponding author on reasonable request.

\section{Declarations}

Competing interests

The authors declare that they have no competing interests.

\section{Author details}

${ }^{1}$ Chair of the Department of Applied Economics, Moscow State Institute of International Relations (MGIMO University), Moscow, Russia. ${ }^{2}$ Department of Theoretical Economics, National Research University Higher School of Economics, Moscow, Russia. ${ }^{3}$ School of Finance and Head of the Research Center of Banking and Risks, National Research University Higher School of Economics, Moscow, Russia.

Received: 1 February 2021 Accepted: 24 May 2021

Published online: 07 June 2021

\section{References}

Acharya V, Pedersen LH, Philippon T, Richardson M (2017) Measuring systemic risk. Rev Financ Stud 30(1):2-47

Adrian T, Brunnermeier M (2016) CoVaR. Am Econ Rev 106(7):1705-1741

Alam Z, Alter A, Eiseman J, Gelos RG, Kang H, Narita M, Nier E, Wang N (2019) Digging deeper-evidence on the effects of macroprudential policies from a new database. IMF Working paper 19/66

Andries A, Melnic F (2019) Macroprudential policies and economic growth. Rev Econ Bus Stud 12(1):95-112

Araujo JD, Patnam M, Popescu A, Valencia F, Yao W (2020) Effects of macroprudential policy: evidence from 6000 estimates. IMF Working paper 20/67

Ayyagari M, BeckT, Martinez Peria M (2018) The micro impact of macroprudential policies: firm-level evidence. IMF Working paper 18/267

Barnichon R, Brownlees C (2019) Impulse response estimation by smooth local projections. Rev Econ Stat 101(3):522-530

Baumeister C, Guérin P (2020) A comparison of monthly global indicators for forecasting growth, NBER Working paper 28014

Baumeister C, Korobilis D, Lee TK (2020) Energy markets and global economic conditions. Rev Econ Stat. https://doi.org/ 10.1162/rest_a_00977

Belkhir M, Naceur SB, Candelon B, Wijnanadts J-C (2020) Macroprudential policies, economic growth, and banking crises, IMF Working paper 20/65

Benoit S, Colliard J-E, Hurlin C, Pérignon C (2017) Where the risks lie: a survey on system risk? Rev Finance 21(1):109-152

Boar C, Gambacorta L, Lombardo G, Pereira da Silva L (2017) What are the effects of macroprudential policies on macroeconomic performance? BIS Q Rev 71-88

Bonciani D, Gauthier D, Kanngiesser D (2021) Slow recoveries, endogenous growth and macroprudential policy. Bank of England Staff Working paper 917

Brandao-Marques L, Gelos G, Narita M, Nier E (2020) Leaning against the wind: a cost-benefit analysis for an integrated policy framework. IMF Working paper 20/123

Brownlees C, Engle RF (2017) SRISK: a conditional capital shortfall measure of systemic risk. Rev Financ Stud 30(1):48-79

Danielsson J, Valenzuela M, Zer I (2020) Financial risk and economic growth, 1870-2016. LSE Systemic Risk Centre Discussion Paper DP 100

Davis PE, Liadze I, Piggot R (2019) Assessing the macroeconomic impact of alternative macroeconomic policies. Econ Model 80:407-428

Dissem S, Lobez F (2020) Correlation between the 2014 EU-wide stress tests and the market-based measures of systemic risk. Res Int Bus Financ 51:100939

Engle R, Jondeau E, Rockinger M (2015) Systemic risk in Europe. Rev Finance 19(1):145-190

Farhi E, Werning I (2016) A theory of macroprudential policy in the presence of nominal rigidities. Econometrica 84(5):1645-1704

Forbes K (2019) Macroprudential policy: what we have learned, don't know and need to know. Am Econ Rev Papers Proc 109:470-475

Franta M, Gambacorta L (2020) On the effects of macroprudential policies on growth-at-risk. Econ Lett 196:109501

Galan JE (2020) The benefits are at the tail: uncovering the impact of macroprudential policy on growth-at-risk. J Financ Stab. https://doi.org/10.1016/j.jfs.2020.100831

Galati G, Moessner R (2013) Macroprudential policy_a literature review. J Econ Surv 27(5):846-878

Galati G, Moessner R (2018) What do we know about the effects of macroprudential policy? Economica 85(340):735-770 
Gambacorta L, Murcia A (2020) The impact of macroprudential policies in Latin America: an empirical analysis using credit registry data. J Financ Intermed 42:100828

Giglio S, Kelly B, Pruitt S (2016) Systemic risk and the macroeconomy: an empirical evaluation. J Financ Econ 119(3):457-471

Grundke P, Tuchsherer M (2019) Global systemic risk measures and their forecasting power for systemic events. Eur J Financ 25(3):205-233

Hamilton J (2021) Measuring global economic activity. J Appl Economet 36(3):293-303

Hodrick R, Prescott E (1997) Postwar U.S. business cycles: an empirical investigation. J Money Credit Bank 29(1):1-16

Hu D, Schwabe G, Li X (2015) Systemic risk management and investment analysis with financial network analytics: research opportunities and challenges. Financ Innov 1, article number: 2

Jerger J, Körner J (2018) Assessing macroprudential regulation: the role of the zero lower bound. Appl Econ Lett 25(9):580-583

Jordá O (2005) Estimation and inference of impulse responses by local projections. Am Econ Rev 95(1):161-182

Kabundi A, De Simone F (2020) Growth and inflation implications of systemic risk in the Euro Area banking industry: lessons from the financial crisis, Mimeo, available at SSRN: https://ssrn.com/abstract=3565803

Kamani E (2019) The effect of non-traditional banking activities on systemic risk: does bank size matter? Financ Res Lett 30:297-305

Kang H, Vitek F, Bhattacharya R, Jeasakul P, Muñoz S, Wang N, Zandvakil R (2017) Macroprudential policy spillovers: a quantitative analysis. IMF Working paper 17/170

Karolyi GA, Stulz R (1996) Why do markets move together? An Investigation of US-Japan Stock Return Comovements. Journal of Finance 51(3):951-986

Kim S, Mehrotra AN (2019) Examining macroprudential policy and its macroeconomic effects-some new evidence. BIS Working paper № 825

Korinek A, Simsek A (2016) Liquidity trap and excessive leverage. Am Econ Rev 106(3):699-738

Kou G, Peng Y, Wang G (2014) Evaluation of clustering algorithms for financial risk analysis using MCDM methods. Inf Sci 275:1-12

Kou G, Chao X, Peng Y, Alsaadi F, Herrera-Viedma E (2019) Machine learning methods for systemic risk analysis in financial sectors. Technol Econ Dev Econ 25(5):716-742

Kucharčuková OB, Claeys P, Vašíček B (2016) Spillover of the ECB's monetary policy outside the euro area: how different is conventional from unconventional policy? J Policy Model 38(2):199-225

Lozano-Vivas A, Pasiouras F (2019) Do macroprudential and monetary policies interact in shaping bank stability? International evidence, Mimeo, available at SSRN: https://ssrn.com/abstract=3492547

Lu W, Gao Y, Huang X (2019) Volatility spillovers of stock markets between China and the countries along the Belt and Road. Emerg Mark Financ Trade 55(14):3311-3331

Lubis A, Alexiou C, Nellis JG (2019) What can we learn from the implementation of monetary and macroprudetial policies: a systematic literature review. J Econ Surv 33(4):1123-1150

Madeira C (2020) The impact of macroprudential policies on industrial growth. Central Bank of Chile Working paper 867 Monin P (2019) The OFR financial stress index. Risks 7(1):25

Norring A (2019) Macroprudential policy spillovers and international banking-taking the gravity approach. ESRB Working paper 101, European Systemic Risk Board

Revelo J, Lucotte Y, Pradines-Jobet F (2020) Macroprudential and monetary policies: the need to dance the tango in harmony. J Int Money Financ 108:102156

Richter B, Schularick M, Shim I (2019) The costs of macroprudential policy. J Int Econ 118:263-282

Rojas D, Vegh CA, Vuletin G (2020) The macroeconomic effects of macroprudential policy: evidence from a narrative approach. NBER Working paper 27687

Rubio M, Yao F (2020) Macroprudential policies in a low interest rate environment. J Money Credit Bank 52(6):1565-1591

Silva W, Kimura H, Sobreiro VA (2017) An analysis of the literature on systemic financial risk: a survey. J Financ Stab 28:91-114

Stolbov M, Shchepeleva M (2018) Systemic risk in Europe: deciphering leading measures, common patterns and real effects. Ann Finance 14:49-91

Stolbov M, Shchepeleva M (2020) Macrofinancial linkages in Europe: evidence from quantile local projections. Int J Financ Econ. https://doi.org/10.1002/ijfe.2080

Tule KM, Odonye OJ, Afangideh UJ et al (2019) Assessing the spillover effects of U.S. monetary policy normalization on Nigeria sovereign bond yield. Financ Innov 5:32

Van der Ghote, A. (2020) Benefits of macro-prudential policy in low interest rate environments, Mimeo

Zeb S, Rashid A (2019) Systemic risk in financial institutions of BRICS: measurement and identification of firm-specific determinants. Risk Manag 21:243-264

\section{Publisher's Note}

Springer Nature remains neutral with regard to jurisdictional claims in published maps and institutional affiliations. 